\section{NLT}

National Institute of

Standards and Technology

U.S. Department of Commerce

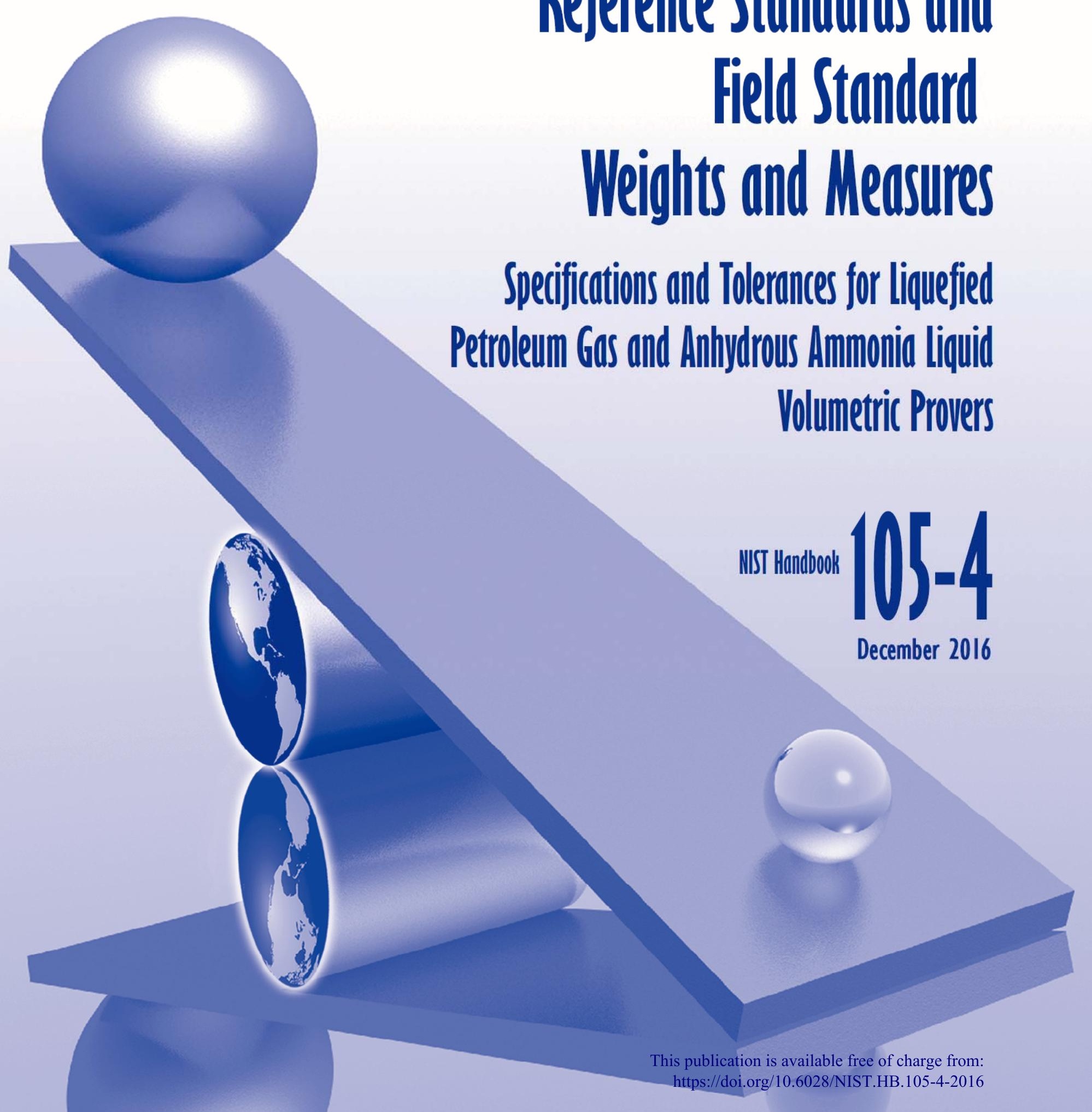

Specifications and Tolerances for Rejerence Standards and

\section{Field Standard}

Weights and Measurues

\section{Sperifications and Tolerances for liquefied}

Petroleum Goss and Anhydrous Ammonia liquid

\section{Volumetric Provers}

December 2016 


\section{Specifications and Tolerances for Reference Standards and \\ Field Standard Weights and Measures}

Specifications and Tolerances for Liquefied Petroleum Gas and Anhydrous Ammonia Liquid Volumetric Provers

Editors:

Georgia L. Harris

Val R. Miller

Georgia L. Harris, Acting Chief

Office of Weights and Measures

Physical Measurement Laboratory

This publication is available free of charge from: https:// doi.org/10.6028/NIST.HB.105-4-2016

December 2016

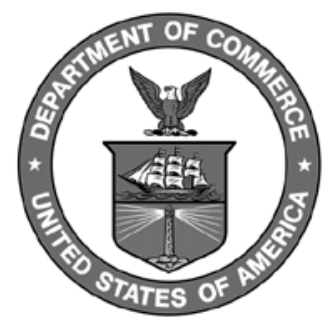

U.S. Department of Commerce Penny Pritzker, Secretary

National Institute of Standards and Technology Willie May, Under Secretary of Commerce for Standards and Technology and Director

NIST

Handbook 105-4

December 2016 Supersedes 2010 Edition 
Specifications and

Tolerances

for Reference Standards

and Field Standard

Weights and Measures

4. Specifications and Tolerances for

Liquefied Petroleum Gas and Anhydrous Ammonia

Liquid Volumetric Provers

$105-4$

NIST

Handbook

December 2016

Supersedes 2010 Edition 


\section{Preface}

NIST Handbook 105-4 contains specifications and tolerances recommended as minimum requirements for standards used by State and local weights and measures officials in the regulatory verification of meters used in quantity determination of pressurized liquid commodities. Other users may find this handbook helpful in the design of volumetric standards for measuring pressurized liquid commodities, but the requirements should not be considered mandatory for special applications outside of the scope of regulatory weights and measures.

\section{Document History and Changes}

This 2016 edition contained minor editorial changes and one major change associated with Section 4.10, Bleed Lines, and the corresponding bleed line section of the evaluation form. Due to several requests and comments associated with zeroing the provers, the acceptability of bleed lines was restored after gathering additional supporting comments and resolving proposed changes with a working group. Final proposed language regarding bleed lines was provided by Henry Oppermann (Seraphin Test Measure Company), with additional supporting comments received and resolved with the working group.

The 2016 revision of Handbook 105-4 includes the following changes:

- No retroactive requirements were added to the document. (2016)

- Liquid bleed lines are reinstated provided safety guidelines are considered. (2016)

The 2010 edition was finalized through a working group consisting of those who provided comments on draft versions, compilation and draft responses of all comments by Michelle Foncannon (NIST), with the final review and editing effort led by L.F. Eason (NIST contract). Special acknowledgment is given to Emil Hazarian, metrologist with the L.A. County and U.S. Navy, Measurement Science Department (retired) for preparing updated drawings and schematic diagrams. Thanks are also given to numerous metrologists (of both state and industry laboratories) for their technical review of several interim drafts. The following changes were made in the 2010 edition.

The 2010 revision of Handbook 105-4 included the following changes since it was first published in 1997:

- The definitions were changed. Liquefied Petroleum Gas (LPG) and anhydrous ammonia provers are pressurized volumetric field standards. A number of references and defined terms have been expanded. (2010)

- Specific references were listed to regulatory and safety requirements for the design of individual components of LPG and anhydrous ammonia provers that are beyond the scope of this document. (2010)

- Series 300 stainless steel was listed as the preferred material due to its corrosion resistance and lower maintenance requirements. (2010) 
- References to "pressure relief" valves and "hydrostatic relief" valves were corrected. (2010)

- Clear coated aluminum was allowed for the scale plate material but all markings must be permanent (allows silk screen). (2010)

- A non-accredited volumetric field standard manufacturer must make it clear that calibration is required before use for Weights and Measures applications. (2010)

- Scale plate graduations must be no smaller in height than $2 \mathrm{~mm}$ (approximately $0.1 \mathrm{in}$ ). (2010)

- The total span of graduations on pressurized volumetric field standards was standardized to be at least $4 \%$ of the nominal volume. (2010)

- The reflex sight gauge must be integral to the neck (upper and lower) of the prover. This change eliminates temperature gradients between the liquid in the sight gauge and the liquid in the body of the prover. (2010)

- Liquid bleed lines were no longer allowed due to the safety and environmental concerns about venting LPG and anhydrous ammonia to the atmosphere. (2010) (Changed in 2016 to allow bleed lines.)

- The level condition of pressurized volumetric field standards is determined by using levels to plumb the neck. The levels on pressurized volumetric field standards must be adjusted to agree with this level condition. (2010)

- The tolerances for pressurized volumetric field standards were changed to $\pm 0.2 \%$ of the nominal capacity. All points on the neck scale must be within this tolerance for the entire volume (not the neck volume). An additional neck uniformity tolerance of two (2) scale divisions from the nominal/zero to any point on the scale also applies. (2010)

- Values in the two tables were updated. (2010)

- The drawings for the figures were updated. (2010)

- An optional evaluation form was added to encourage uniform evaluation of pressurized volumetric field standards. (2010)

The first several drafts of this Handbook were written by James Clifford, metrologist with the State of Oregon. The first published edition was in 1997 and drafts were updated with assistance of Karl Herken, metrologist with the State of Kansas. 
NOTE Regarding Units of Measure:

The SI base unit of volume is the cubic meter $\left(\mathrm{m}^{3}\right)$. The Twelfth General (International) Conference on Weights and Measures redefined the litre [herein spelled liter] as a "special name for the cubic decimeter," but agreed to permit the continuance of the terms liter (L) and milliliter $(\mathrm{mL})$, except in association with measurements of the highest precision. The commercial measurement system in the United States continues to use gallons and cubic inches for practical applications and manufacturers in this industry continue to use U.S. Customary dimensions. Since commercial applications in the United States use units other than SI or other accepted metric units, this document references common units in current use.

*Trade names used in this Handbook do not imply recommendation or endorsement by the National Institute of Standards and Technology. 


\section{Table of Contents}

Preface

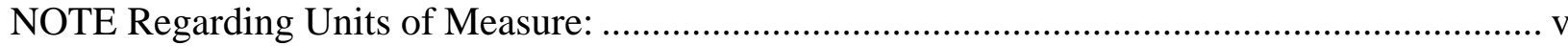

Introduction $\quad$.

"Field Standard" Classification....

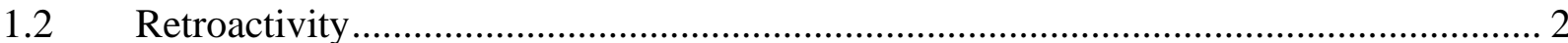

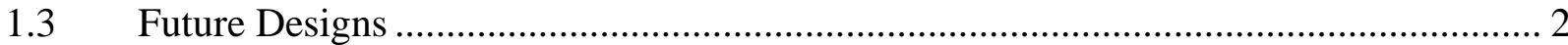

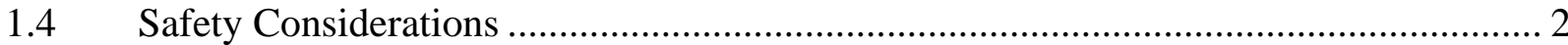

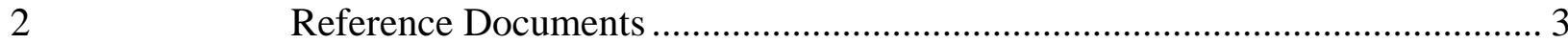

$2.1 \quad$ American National Standards Institute (ANSI) ............................................................. 3

$2.2 \quad$ American Petroleum Institute (API) ......................................................................... 3

2.3 American Society for Mechanical Engineers (ASME)..................................................... 3

2.4 American Society for Testing and Materials (ASTM) ……………………................ 3

2.5 International Organization of Legal Metrology (OIML) ................................................ 4

$2.6 \quad$ International Society of Automation (ISA).................................................................. 4

2.7 National Fire Protection Association (NFPA) ………….............................................. 4

2.8 National Institute of Standards and Technology (NIST), Office of Weights and

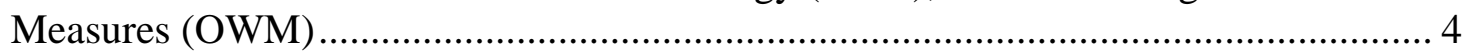

$2.9 \quad$ Underwriters Laboratories (UL) .............................................................................. 4

2.10 US Department of Labor, Occupational Safety and Health Administration (OSHA).... 5

$3 \quad$ Terminology..................................................................................... 5

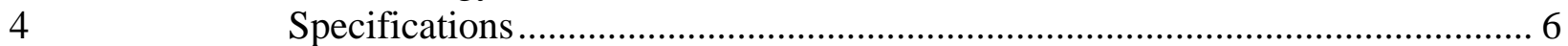

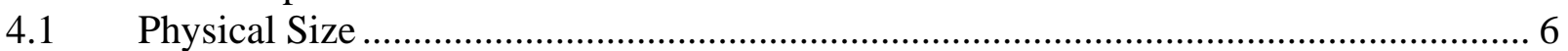

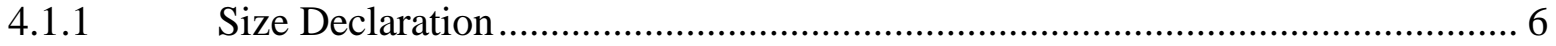

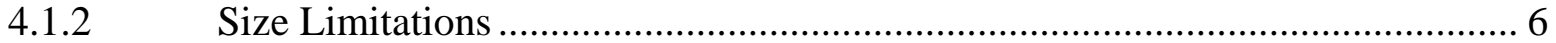

4.2 Reference Temperature and Pressure.......................................................................... 7

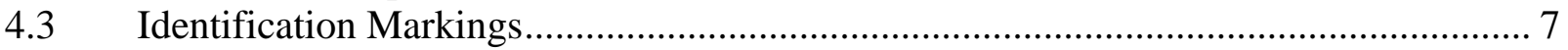

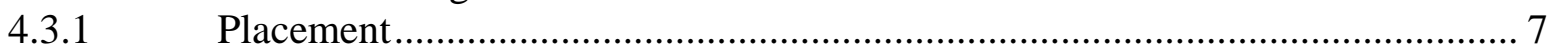

4.3.2 Identification Plate Content ......................................................................... 7

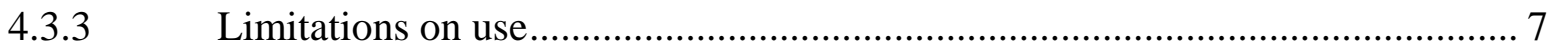

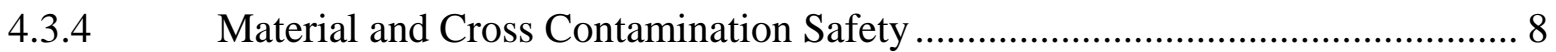

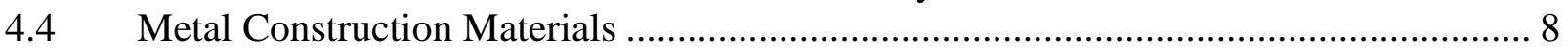

4.4.1 ASME Pressure Vessel Requirements ............................................................... 8

4.4.2 Pressurized Provers for Testing LP Gas Meters ……………………….............. 8

4.4.3 Pressurized Provers for Testing Anhydrous Ammonia Meters ............................ 8

4.4.4 Associated Pressurized Hardware............................................................... 9

4.4.5 Associated Non-Pressurized Hardware ...................................................... 9

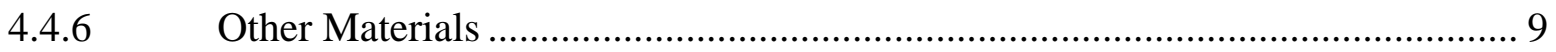

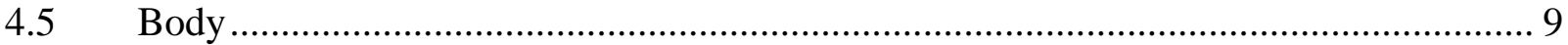

4.5.1 Pressure Vessel Compliance ........................................................................ 9

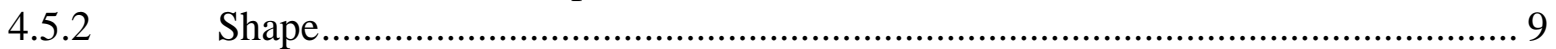

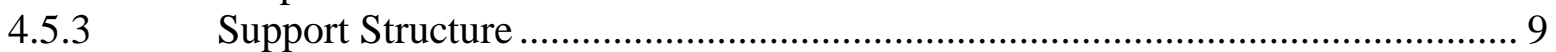

4.6 Upper and Lower Necks .................................................................................... 10

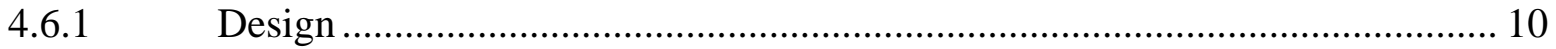

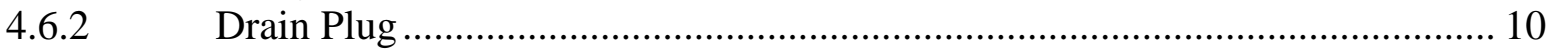




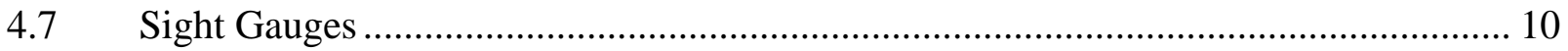

4.7.1 Upper Sight Gauge................................................................................ 10

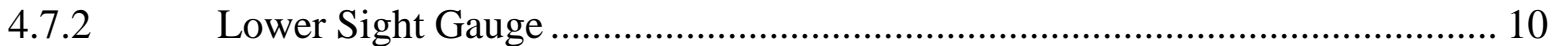

4.7.3 Sight Gauge Mounting Plate .......................................................................... 10

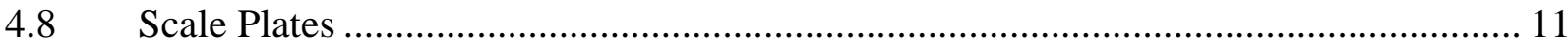

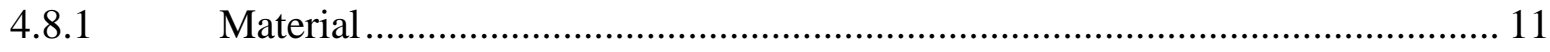

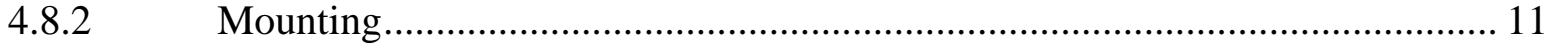

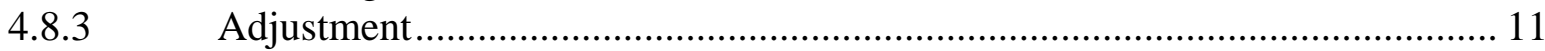

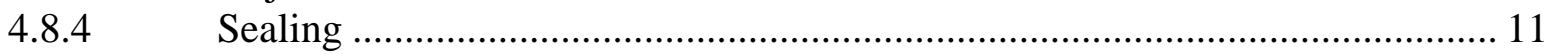

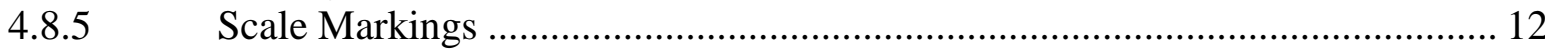

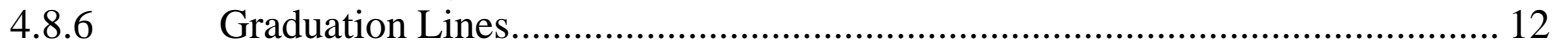

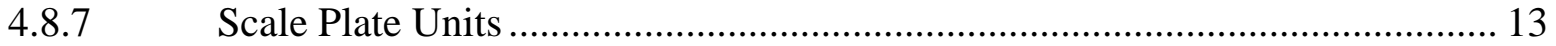

4.8.8 Dual Scale Calibration ............................................................................... 13

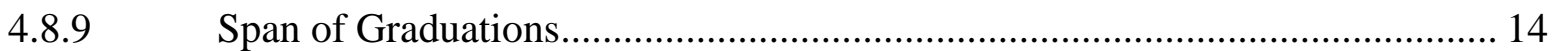

$4.9 \quad$ Fill and Discharge (Pump Off) Lines and Valves........................................................ 14

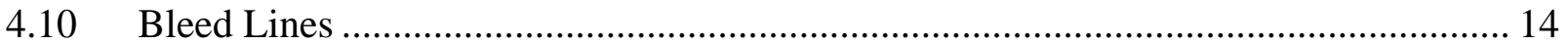

4.10.1 Anhydrous Ammonia Provers ............................................................... 14

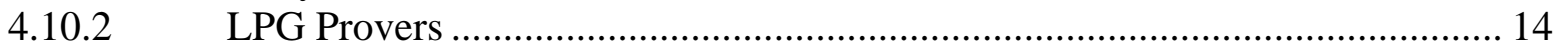

4.11 Thermometer Wells and Thermometers ................................................................ 14

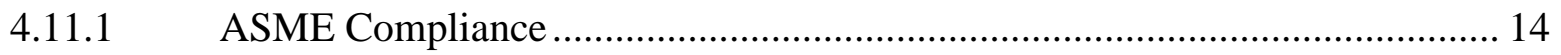

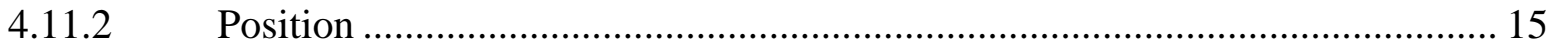

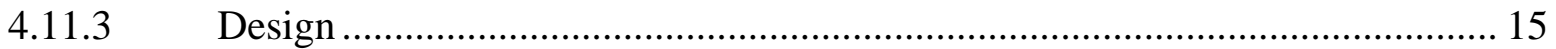

4.11.4 Installation in Thermometer Wells …………................................................. 15

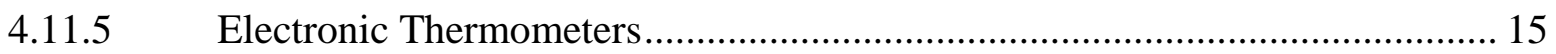

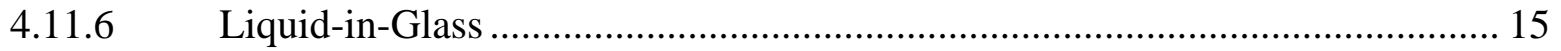

4.11.7 Bi-Metal Dial Face Thermometers ………........................................................ 15

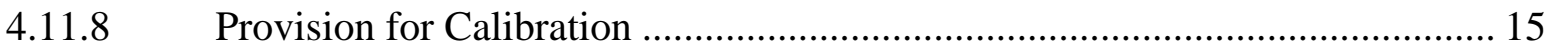

4.11.9 Additional Thermometer Wells ................................................................ 16

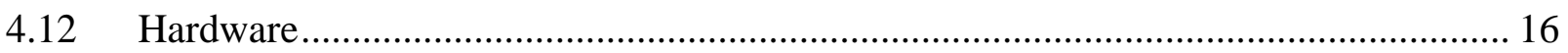

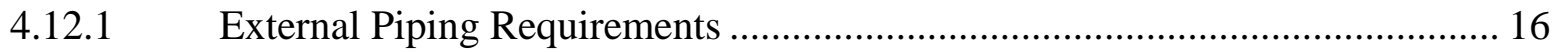

4.12.2 Pressure Gauge .................................................................................. 16

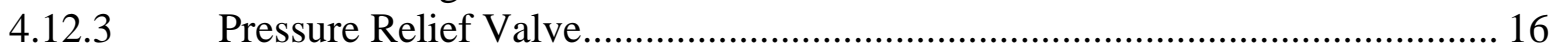

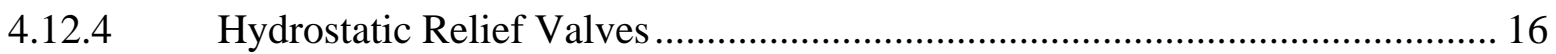

4.12.5 Excess Flow Valves and Back Check Valves................................................... 17

4.12.6 Vapor Pressure Equalization.......................................................................... 17

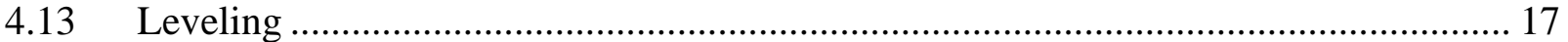

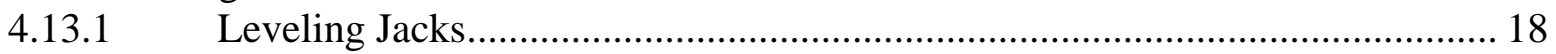

4.13.2 Establishment of Level Condition .............................................................. 17

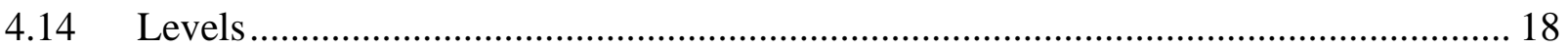

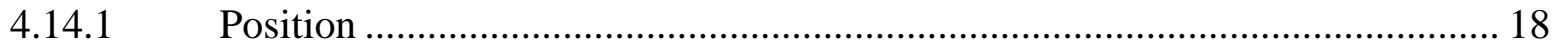

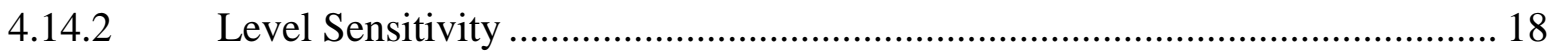

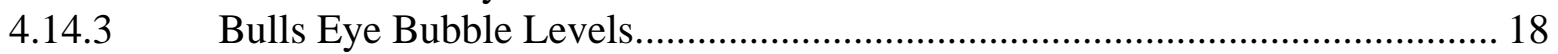

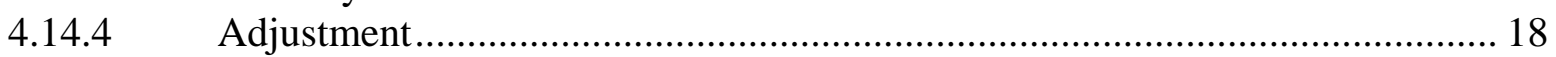

4.14.5 Auxiliary Levels ................................................................................... 18

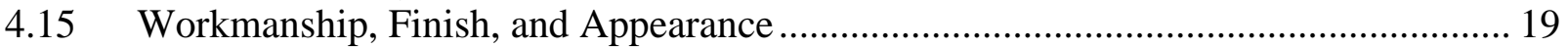

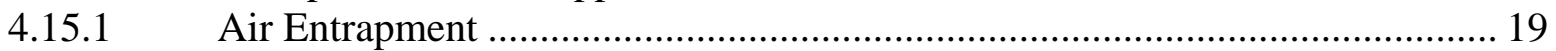


4.15.2 Finished Quality.......................................................................................... 19

4.15.3 Required Assemblies .............................................................................. 19

4.15.4 Thread Connector Lubricant.................................................................. 19

4.15.5 Valve Operation......................................................................................... 19

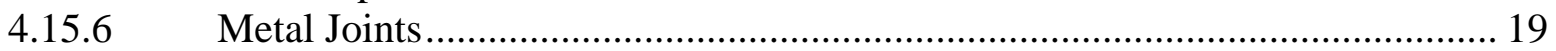

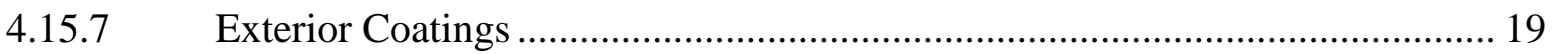

4.16 Other Requirements ........................................................................................... 19

4.16.1 Return Pump ……………………............................................................ 20

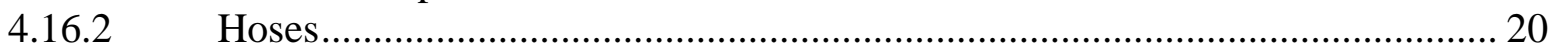

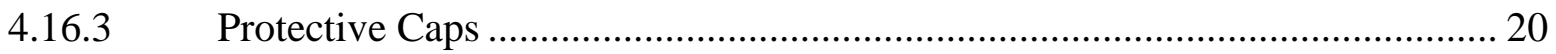

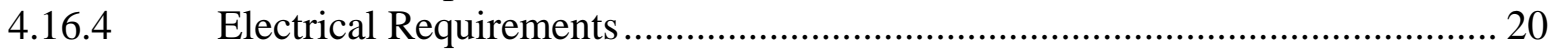

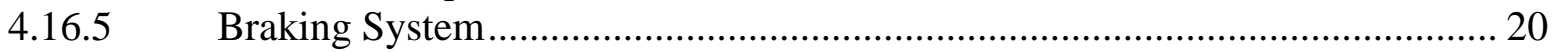

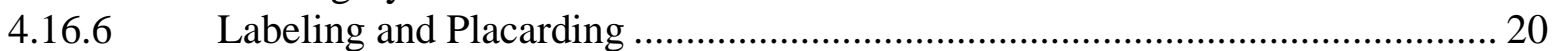

$5 \quad$ Tolerances (Maximum Permissible Errors) ..................................................... 20

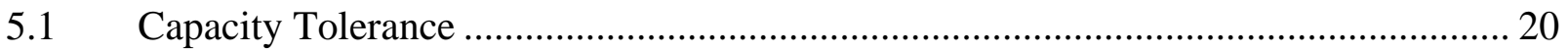

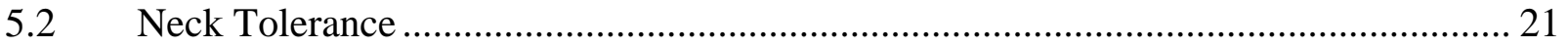

5.2.1 Neck Calibration Tolerance ......................................................................... 21

5.2.2 Neck Uniformity Tolerance ........................................................................ 21

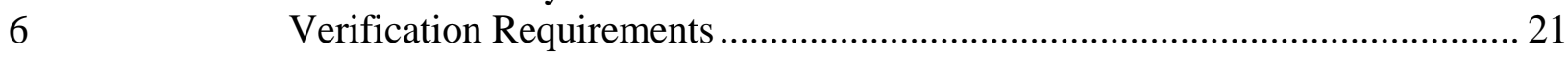

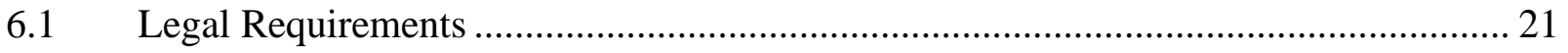

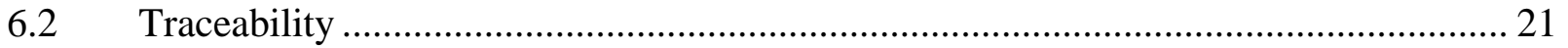

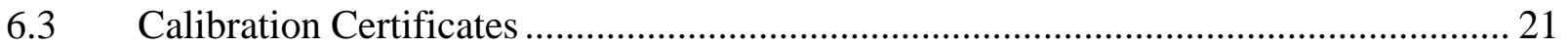

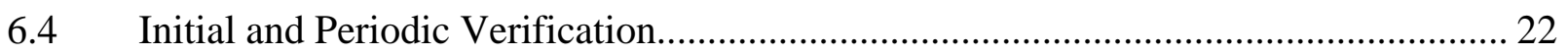

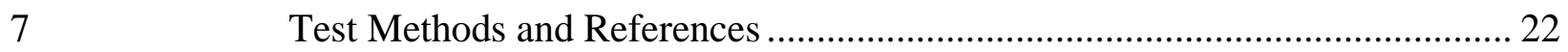

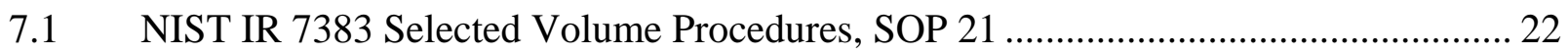

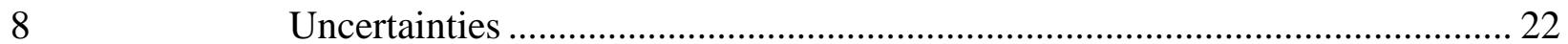

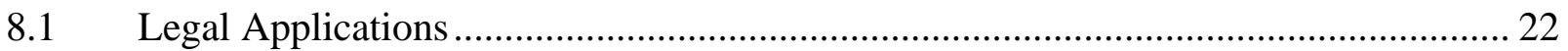

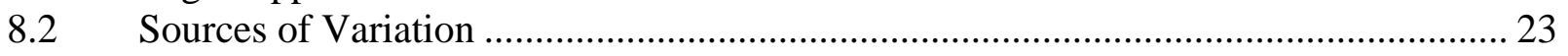

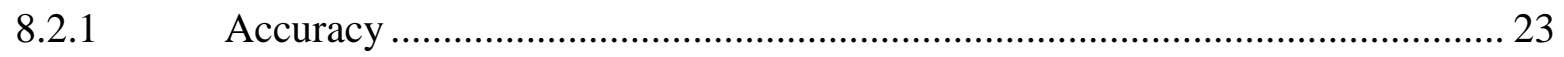

8.2.2 Repeatability ............................................................................................ 24

Table 1. Metric specifications and tolerances for pressurized volumetric field standards

Table 2. U.S. Customary specifications and tolerances for pressurized volumetric field

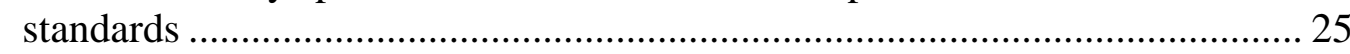

Appendix 1. Optional LPG and Anhydrous Ammonia Pressurized Volumetric Field Standards Evaluation Form......................................................................... 26

Figure 1. Schematic Drawing of a LPG and Anhydrous Ammonia Prover and Associated Hardware/Plumbing..................................................................................... 28

Figure 2. $\quad$ Schematic Drawing of Gauge Plates (Top and Bottom).................................. 29

Figure 3. 100 gal Retention Plate (schematic). ................................................................ 30

Figure 4. Schematic for Use of Prover in Meter Verification............................................ 31

References 


\title{
SPECIFICATIONS AND TOLERANCES \\ FOR REFERENCE STANDARDS AND FIELD STANDARD \\ WEIGHTS AND MEASURES
}

\author{
4. Specifications and Tolerances for \\ Liquefied Petroleum Gas and Anhydrous Ammonia \\ Liquid Volumetric Provers
}

These specifications and tolerances are recommended as minimum requirements for standards used by State and local weights and measures officials and others in the regulatory verification of meters used in quantity determination of pressurized liquid commodities. Other users may find this handbook helpful in the design of volumetric standards for measuring pressurized liquid commodities, but the requirements should not be considered mandatory for special applications outside of the scope of regulatory weights and measures.

Key words: $\quad$ back check valve; excess flow valve; hydrostatic relief valve; pressure vessels; pressure relief valve; pressurized volumetric field standards; provers; specifications; vapor return; volumetric specifications and tolerances; weights and measures.

\section{Introduction}

Pressurized volumetric field standards (pressurized provers) are used primarily to test commercial pressurized liquid measuring devices for compliance with commercial requirements. Use of these field standards at all appropriate levels of manufacture, distribution, and weights and measures inspection will help promote accuracy and uniformity in commerce. The breadth of topics in this handbook is intended to provide information for manufacturers, calibration staff, weights and measures officials, and other end users. References are provided when additional information may be useful to the reader.

\section{Scope}

\section{1 “Field Standard” Classification}

These specifications and tolerances are limited to pressurized, graduated neck type volumetric field standard provers. The field standards covered by this publication are intended to be used by weights and measures officials. Manufacturers and distributors of liquefied gases, service maintenance personnel, research and testing laboratories, and others concerned with volume measurements of pressurized liquids may find these specifications and tolerances useful. Use of these standards at all appropriate levels of manufacture, distribution, and weights and measures inspection will help promote accuracy and uniformity in commerce.

The terms "pressurized volumetric field standard”, "pressurized prover”, and "prover” as used in this publication refer to all sizes in general. The pressurized provers referenced here are those whose volume is established between a graduated bottom zero and the nominal volume point on the graduated neck scale, when pressurized to $689.4757 \mathrm{kPa}$ (100 pounds per square inch gauge, or "psig"). The unit psig will be used hereafter to reflect the pressures in common usage in the United States. 
In some cases larger or special purpose pressurized provers may be required which are outside of the scope of this publication. For example, a large truck or trailer mounted pressurized volumetric field standard may be transported in a horizontal position and raised to vertical for use. Larger volumetric field standards may be built based on design considerations within this document, but they are not specifically covered. Additional performance, structural integrity, stability, and safety issues applicable to these larger standards, though outside of the scope of this handbook, must be considered.

\subsection{Retroactivity}

These specifications are not intended to make obsolete those field standards fabricated to meet prior specifications. All new pressurized volumetric field standards (provers) placed in service after March 1, 2010, must meet these requirements prior to certification for regulatory Weights and Measures (legal metrology) use.

Pressurized volumetric field standards fabricated to meet prior specifications may be used as long as they 1) comply with applicable ASME and NFPA requirements, 2) maintain the current tolerances, 3) meet the calibration repeatability requirement of $0.02 \%$ of nominal volume, and 4 ) their performance is adequate to meet NIST Handbook 44 fundamental considerations (i.e., the correction plus the measurement uncertainty does not exceed one-third of the tolerance for the device being tested).

\subsection{Future Designs}

These specifications are not intended to limit innovation made possible by advances in technology or changes in the commercial field devices they are used to test. All design revisions should be evaluated by NIST for accuracy, repeatability, and suitability for task. Approved design revisions may be included in future revisions of this document.

\subsection{Safety Considerations}

This documentary standard involves hazardous materials, operations, and equipment and does not purport to address the safety problems associated with its use. It is the responsibility of the user of this standard to establish appropriate safety and health practices and determine the applicability of regulatory limitations prior to use. Specific safety information is documented in the American Petroleum Institute (API) references.

Although these specifications include pressurized volumetric field standards for liquefied petroleum gas (LPG) and anhydrous ammonia, these products cannot be interchanged in the use of the standard. Cross contamination of either product would create additional safety hazards to the inspector and user of the products. The user should evaluate all components of the system to ensure compatibility with the intended product to be measured.

Commercial volume measuring devices tested with these field standards are typically used to measure quantities of LPG, anhydrous ammonia, and other pressurized liquids in sealed systems. These liquids are known hazardous materials and hazardous wastes if spilled/released. The user is encouraged to obtain Material Safety Data Sheets (MSDS), also called Safety Data Sheets (SDS), from the manufacturer of any product encountered. Federal and local safety and disposal regulations concerning hazardous materials encountered should be reviewed by the user. 
Ethyl mercaptan (ethanethiol) is added to LPG to make it easier to detect in case of a leak. It has a very strong odor that is detectable in very small concentrations. Anhydrous ammonia also has a very pungent odor. It is very caustic and hazardous. Therefore, field standards should be purged of product and the interior be thoroughly flushed with water prior to being submitted for test. These calibrations should be conducted in a well ventilated area.

This handbook does not address possible emissions from field standards during their use in the testing of hydrocarbons or ammonia. Please note that venting propane in some situations may be prohibited by law.

\section{Reference Documents}

Specifications in this handbook are based in part upon information contained in publications from various standards and safety organizations. Due to the hazardous nature of the products being measured, there are safety regulations and references for all major components of liquefied petroleum gas and anhydrous ammonia pressurized volumetric field standards. The following is a list of reference documents pertaining to liquefied petroleum gas and anhydrous ammonia regulations and safety engineering. These documents detail requirements for each component of liquefied petroleum gas and anhydrous ammonia pressurized volumetric field standards. This handbook is intended to be in compliance with the requirements of these documents. However, if a conflict is found between this handbook and the current version of the references cited below, the requirements of the regulatory agency cited supersede the requirements of this document. Any conflicts found should be brought to the attention of the NIST, Office of Weights and Measures (OWM) to be included in future revisions of this document.

\subsection{American National Standards Institute (ANSI) ${ }^{1}$}

2.1.1 ANSI/ISA RP12.06.01, Recommended Practice for Wiring Methods for Hazardous (Classified) Locations Instrumentation Part 1: Intrinsic Safety.

\subsection{American Petroleum Institute (API) ${ }^{2}$}

2.2.1 Manual of Petroleum Measurement Standards, Chapter 11.2.4, Temperature Correction for the Volume of NGL and LPG Tables 23E, 24E, 53E, 54E, 59E, 60E.

2.2.2 Manual of Petroleum Measurement Standards, Chapter 14.8, Liquefied Petroleum Gas Measurement.

\subsection{American Society for Mechanical Engineers (ASME) ${ }^{3}$}

2.3.1 ASME International Boiler and Pressure Vessel Code, Section VIII, Pressure Vessels.

\subsection{American Society for Testing and Materials (ASTM) ${ }^{4}$}

2.4.1 ASTM D1250 - 08(2013)e1 Standard Guide for Use of the Petroleum Measurement Tables.

2.4.2 Table 24, Volume Reduction to $60^{\circ} \mathrm{F}$.

2.4.2.1 Table 24B, Generalized Products, Correction of Volume to $60^{\circ} \mathrm{F}$ against Relative Density 60/60 ${ }^{\circ} \mathrm{F}$. 
2.4.3 Table 34, Reduction of Volume to $60^{\circ} \mathrm{F}$ against S.G. $60 / 60^{\circ} \mathrm{F}$ for Light Petroleum Gases.

\subsection{International Organization of Legal Metrology (OIML) ${ }^{5}$}

2.5.1 International Recommendation, OIML R 117-1, Edition 2007 (E), Dynamic measuring systems for liquids other than water, Part 1: Metrological and technical requirements.

2.6 International Society of Automation (ISA) ${ }^{6}$

2.6.1 See ANSI/ISA RP12.06.01 referenced under ANSI above.

2.7 National Fire Protection Association (NFPA) ${ }^{7}$

2.7.1 NFPA 54, National Fuel Gas Code.

2.7.2 NFPA 58, Liquefied Petroleum Gas Code.

2.7.3 NFPA 58HB, LP-Gas Code Handbook.

2.7.4 NFPA 70, National Electrical Code.

2.8 National Institute of Standards and Technology (NIST), Office of Weights and Measures (OWM) ${ }^{8}$

2.8.1 Handbook 44, Specifications, Tolerances, and Other Technical Requirements for Weighing and Measuring Devices, see current edition, published annually.

2.8.2 NISTIR 7383, Selected Procedures for Volumetric Calibrations, Standard Operating Procedure, 21, Calibration of LPG Provers. See current edition.

2.8.3 NIST Handbook 105-6, Specifications and Tolerances for Reference Standards and Field Standard Weights and Measures, 6. Specifications and Tolerances for Thermometers. See current edition.

\subsection{Underwriters Laboratories (UL) ${ }^{9}$}

2.9.1 UL Standard 21, LP-Gas Hose.

2.9.2 UL Standard 25, Meters for Flammable and Combustible Liquids and LP-Gas.

2.9.3 UL Standard 51, Power-Operated Pumps for Anhydrous Ammonia and LP-Gas.

2.9.4 UL Standard 125, Valves for Anhydrous Ammonia and LP-Gas (Other Than Safety Relief).

2.9.5 UL Standard 132, Safety Relief Valves for Anhydrous Ammonia and LP-Gas.

2.9.6 UL Standard 331, Strainers for Flammable Fluids and Anhydrous Ammonia.

2.9.7 UL Standard 495, Power-Operated Dispensing Devices for LP-Gas.

2.9.8 UL Standard 565, Liquid-Level Gauges and Indicators for Anhydrous Ammonia and LPGas.

2.9.9 UL Standard 567, Emergency Breakaway Fittings, Swivel Connectors and PipeConnection Fittings for Petroleum Products and LP-Gas.

2.9.10 UL Standard 569, Pigtails and Flexible Hose Connectors for LP-Gas.

2.9.11 UL Standard 644, UL Standard for Safety for Container Assemblies for LP-Gas. 
2.9.12 UL Standard 1203, Explosion-Proof and Dust-Ignition Electrical Equipment for Use in Hazardous (Classified) Locations.

2.9.13 UL Standard 2061, Adapters and Cylinder Connection Devices for Portable LP-Gas Cylinder Assemblies.

2.9.14 UL Standard 60079, Electrical Apparatus for Explosive Gas Atmospheres.

\subsection{US Department of Labor, Occupational Safety and Health Administration (OSHA) ${ }^{10}$}

2.10.1 29 CFR, Part 1910 Occupational Safety and Health Standards, Subpart H - Hazardous Materials.

2.10.1.1 Standard 1910.101 - Compressed gases (general requirements).

2.10.1.2 Standard 1910.110 - Storage and handling of liquefied petroleum gases.

2.10.1.3 Standard 1910.111 - Storage and handling of anhydrous ammonia.

\section{Terminology}

Anhydrous Ammonia. A relatively pure, very caustic and hazardous, form of ammonia, synthesized from nitrogen and hydrogen, combined at high temperatures and pressures in the presence of a catalytic agent. Used primarily as a fertilizer, or a refrigerant. It will react rapidly with copper, brass, zinc and many alloys, especially those containing copper. It boils at atmospheric pressure at $-33.3^{\circ} \mathrm{C}\left(-27.9^{\circ} \mathrm{F}\right)$. Anhydrous Ammonia will contaminate LPG.

Back check valve. A valve designed to automatically prevent liquid or vapor from flowing in the wrong direction.

Capacity, nominal. The nominal capacity of a volumetric field standard is the volume used to designate the prover (e.g., 100 gal LPG prover). The nominal volume is defined between the nominal mark on the graduated upper neck gauge and the lower zero mark on a lower neck gauge on an LPG / anhydrous ammonia prover.

Cubical coefficient of thermal expansion. Three dimensional expansion or contraction of a material due to temperature change, expressed ${ }^{\circ} \mathrm{C}^{-1}$ or ${ }^{\circ} \mathrm{F}^{-1}\left({ }^{\circ} \mathrm{C}\right.$ or $\left./{ }^{\circ} \mathrm{F}\right)$.

Excess-Flow Valve (also called excess-flow check valve). A device designed to close, reducing or stopping the flow when the liquid or vapor passing through it exceeds a prescribed flow rate as determined by pressure differential. This is a safety device primarily designed to cut off flow in case of a ruptured line or hose.

Hydrostatic Relief Valve. A pressure relief valve designed to protect liquid-filled piping from excessive pressure and possible rupture.

Liquefied Petroleum Gas (LPG). Means a mixture of normally gaseous hydrocarbons, predominantly propane, or butane, or both, that has been liquefied by compression, cooling, or both to facilitate storage, transportation, and handling.

Plumb. The condition of being perpendicular to a horizontal plane, vertical.

Pressure Gauge. A calibrated test device capable of sensing and indicating from 0 psig to 300 psig in 5 psig increments (as applied to this specification). 
Pressure Relief Valve. A pressure relief valve designed to protect piping that is not in contact with liquid (i.e., a vapor return line) from excessive pressure and possible rupture.

Pressurized Prover. A mounted volumetric field standard (truck, trailer, or stationary) built to ASME Pressure Vessel Code specifications designed to test liquefied propane gas, anhydrous ammonia, or other liquids in a closed system at the pressure needed to maintain a liquid state at ambient temperatures.

Reference temperature. The temperature at which the pressurized volumetric field standard is intended to deliver its nominal capacity.

Reflex Sight Gauge. A liquid level gauge, designed in such a way as to cause the liquid level to disrupt the refraction of light, causing the liquid within the gauge to appear black.

Sight Flow Indicator. A fitting with windows, to visually observe flow through a pipe; may or may not be equipped with a mechanical flow indicator.

Standard. Physical realization or representation of a unit of measure. In the context of this handbook standard may mean a laboratory standard or a field standard.

Tolerance. Maximum permissible error: extreme value of measurement error, with respect to a known reference quantity value, permitted by specifications or regulations for a given measurement, measuring instrument, or measuring system.

\section{$4 \quad$ Specifications}

\subsection{Physical Size}

\subsubsection{Size Declaration}

The nominal volumes of pressurized volumetric field standards (pressurized provers) are represented by the nominal volume lines located on their upper scale plates. Recommended metric sizes are shown in Table 1 and U.S. Customary (inch-pound) sizes are shown in Table 2 at the end of this document. Nominal volumes in each system are ideally selected in multiples of 1,2 , and 5 (liters or gallons) to facilitate calibration. However, a prover may be built to any size to meet specific needs and which may be practically calibrated. Non-standard size volumetric field standards that comply with all other requirements shall be considered to be in full compliance with this standard.

\subsubsection{Size Limitations}

The largest pressurized volumetric field standard described in this document is $2000 \mathrm{~L}$ (500 gal). Truck or trailer mounted provers must meet legal weight and width regulations. This will typically limit the maximum size of pressurized volumetric field standards (pressurized provers) intended for portable operation. Pressure vessel design limitations along with practical and available calibration methods will typically limit the size of stationary provers. Exceptions to these size limitations may be made for special applications if proper engineering and safety considerations are followed, but these special application provers are outside the scope of this document. 


\subsection{Reference Temperature and Pressure}

The following reference conditions shall be applied to pressurized volumetric field standards (pressurized provers) when calibrated to deliver a volume equal to its nominal capacity: $60{ }^{\circ} \mathrm{F}$ $\left(15.56^{\circ} \mathrm{C}\right)$ and 100 psig. International standards typically reference petroleum products to $15^{\circ} \mathrm{C}$. Temperature and pressure measurements shall meet the accuracy requirements of the procedure chosen and be traceable to national standards. The uncertainty of the calibration must be adequate to meet NIST Handbook 44 fundamental considerations (correction plus uncertainty does not exceed one-third of the tolerance for the device being tested). During use of pressurized volumetric field standards all measurement indications must be corrected to the reference temperature and pressure for correct application of meter tolerances.

\subsection{Identification Markings}

\subsubsection{Placement}

Identification information shall be engraved, embossed, or otherwise permanently placed on a stainless steel plate. The stainless steel plate must meet the requirements and be attached in accordance with National Fire Protection Association (NFPA) 58, Liquefied Petroleum Gas Code. All lettering shall be permanent, durable, weather resistant, impervious to the liquids the volumetric field standard is intended to measure, and if not engraved or embossed, of a contrasting color to that of the background of the data plate. This information (however placed) should be either laminated or coated with a clear protective coating to preserve its legibility indefinitely.

\subsubsection{Identification Plate Content}

Each identification plate shall be attached in a conspicuous place on the standard and shall bear the following information:

\subsubsection{Nominal capacity;}

4.3.2.2 Reference temperature for calibration;

4.3.2.3 Name and address of manufacturer;

4.3.2.4 Model number;

4.3.2.5 Non-repetitive serial or identification number;

4.3.2.6 Material identification;

4.3.2.7 Cubical coefficient of thermal expansion of material;

4.3.2.8 Drain time after cessation of main flow or the total drain time

4.3.2.9 Proof of ASME certification;

4.3.2.10 Maximum allowable working pressure;

4.3.2.11 Date and pressure to which hydrostatically tested; and

4.3.2.12 Inside diameters of upper and lower necks.

\subsubsection{Limitations on use}

Any limitations on use shall be clearly and permanently marked on any volumetric field standard intended to measure accurately only: 
4.3.3.1 Products having particular properties (i.e., anhydrous ammonia will contaminate LP gas); 4.3.3.2 Under specific installation or operating conditions; or 4.3.3.3 When used in conjunction with specific accessory equipment.

\subsubsection{Material and Cross Contamination Safety}

Care shall be taken to ensure that the materials used for the volumetric field standards, or any subsequent contamination of such materials, do not create a safety hazard.

NOTE: A pressurized volumetric field standard prover must be properly labeled and placarded according to DOT operational rules, NFPA 58, and other regulatory requirements. Local laws and regulations vary between jurisdictions. It is incumbent upon the user of a pressurized volumetric field standard prover to be aware of and comply with local laws and regulations regarding the labeling and placarding of pressurized volumetric field standard used to test hazardous materials.

\subsubsection{Product Labeling}

The user shall appropriately label a pressurized volumetric field standard in a conspicuous place according to the product it will be used to test. Labeling shall include "Anhydrous Ammonia Only", "LPG Only", or other similar identification of the specific type of pressurized liquid the standard will be used to test.

\subsubsection{Multiple Products}

If the standard is to be used for multiple products, all products that may be tested must be labeled with additional labeling detailing the method of purging or cleaning required between different products.

\subsection{Metal Construction Materials}

\subsubsection{ASME Pressure Vessel Requirements}

A pressurized volumetric field standard shall meet the requirements of Section VIII, Pressure Vessels of the American Society for Mechanical Engineers (ASME), International Boiler and Pressure Vessel Code.

\subsubsection{Pressurized Provers for Testing LP Gas Meters}

A pressurized volumetric field standard used to test LP gas meters shall be constructed of either 300 series stainless steel (preferred) or low carbon steel. Construction must comply with all ASME pressure vessel requirements. 300 series stainless steel is more resistant to corrosion of the interior walls of the vessel and is the strongly preferred material. Corrosion of low carbon steel will cause the bottom sight gauge to become dirty and difficult to read. Since the sight gauges on pressurized volumetric field standards are not readily accessible for cleaning and a sight glass cannot be reused after removal, frequent replacement of sight gauges (and recalibration) is required. Corrosion will also eventually weaken the vessel.

\subsubsection{Pressurized Provers for Testing Anhydrous Ammonia Meters}

Due to the corrosive nature of anhydrous ammonia, a pressurized volumetric field standard used to test anhydrous ammonia meters shall be constructed of 300 series stainless steel. 


\subsubsection{Associated Pressurized Hardware}

Piping, valves, fittings, handles and other associated hardware that are subjected to pressure may be constructed of other materials, provided they are compatible with the product tested and meet all applicable American Society for Mechanical Engineers (ASME) requirements. In addition, all pressurized hardware and fittings must meet National Fire Protection Association (NFPA), Underwriters Laboratories (UL), and US Department of Labor, Occupational Safety and Health Administration (OSHA) safety requirements, and any other regulatory requirements, including those requiring periodic maintenance, requalification, or replacement.

\subsubsection{Associated Non-Pressurized Hardware}

Brackets, fittings, handles and other associated hardware that are not subjected to pressure may be constructed of other materials, provided they are durable and are suitable for their intended purpose. These materials must also meet all applicable regulatory and safety requirements.

\subsubsection{Other Materials}

These specifications are not intended to preclude the use of other suitable materials, provided such materials conform to all ASME pressure vessel requirements, associated agency regulatory and safety requirements, and the applicable parts of these specifications. The material shall be of sufficient strength, shall be thermally stable, and not have an unduly high coefficient of thermal expansion which would render it unsuitable for field use. All applicable physical properties data must be accurately documented for the material chosen. Interested parties are urged to submit proposed designs to the National Institute of Standards and Technology (NIST), Office of Weights and Measures (OWM) for evaluation before fabrication is begun.

NOTE: These pressurized volumetric field standards are ASME containers. They do not meet the definition of a DOT container for DOT maintenance requirements. Therefore, periodic hydrostatic testing is typically not required. However, if local regulatory authorities do require a pressurized volumetric field standard to be hydrostatically tested, the standard should be recalibrated after testing since the hydrostatic test will expand the vessel slightly.

\subsection{Body}

\subsubsection{Pressure Vessel Compliance}

A pressurized volumetric field standard shall comply with all applicable requirements of Section VIII, Pressure Vessels of the American Society for Mechanical Engineers (ASME) International Boiler and Pressure Vessel Code. A LPG prover shall have a maximum allowable working pressure (MAWP) of 250 psig. An anhydrous ammonia prover shall have a maximum allowable working pressure (MAWP) of 300 psig.

\subsubsection{Shape}

Any cross section taken in a plane perpendicular to the vertical axis shall be circular, and the shape shall ensure complete emptying and draining. The volume of a prover shall be established without the use of fillers, adjusting plugs, or cavities of any kind.

\subsubsection{Support Structure}

The support structure of the pressurized volumetric field standard, consisting of legs and framework shall be attached to reinforcement plates on the body of the prover. The attachment 
method of the support structure shall not contribute to prover deformation when routinely transported on a trailer or when fully loaded.

\subsection{Upper and Lower Necks}

Upper and lower neck maximum diameter requirements are given in Tables 1 and 2 for different nominal volumes. Additional specifications are listed below.

\subsubsection{Design}

The upper and lower neck shall be seamless pipe, smooth inside, and specially inspected and selected for uniformity in the circular cross section. The upper and lower neck axes shall be perpendicular to a level horizontal plane.

\subsubsection{Drain Plug}

The lower neck shall be provided with a threaded plug to facilitate cleaning for calibration and completely drain the prover after calibration. The bottom should have a slight slope to facilitate drainage of prover through the drain plug.

\subsection{Sight Gauges}

A pressurized volumetric field standard shall be equipped with two liquid level gauges of the reflex type mounted as an integral part of the upper and lower neck. The liquid level gauges and retaining plates shall meet the requirements of UL Standard 565, Liquid-Level Gauges and Indicators for Anhydrous Ammonia and LP-Gas and all applicable ASME requirements.

\subsubsection{Upper Sight Gauge}

The sight gauge shall be capable of displaying a volume not less than $4 \%$ of the prover nominal volume.

NOTE: Available sight gauges can display more than $4 \%$ of the prover nominal volume. This design extends the application of the prover for the user.

\subsubsection{Lower Sight Gauge}

A pressurized volumetric field standard shall have a bottom zeroing capability (also called wet zero). The wet zero shall have a similar type liquid level gauge as the top neck adequate for establishing the zero set-point. To facilitate the ability to see and stop the liquid drain in time to set the zero, the lower sight gauge assembly shall display a minimum length of $10 \mathrm{~cm}$ (approximately 6 in) of liquid level in the lower neck.

\subsubsection{Sight Gauge Mounting Plate}

The width of the opening in the sight gauge mounting plates (upper and lower) shall be at least $12.7 \mathrm{~mm}$ (0.5 in) to allow for a clear view of the liquid level in the sight gauge.

NOTE: The sight gauge and mounting plate must meet the requirements of Section VIII, Pressure Vessels, of the ASME, International Boiler and Pressure Vessel Code. If an opening of $12.7 \mathrm{~mm}$ (0.5 in) or larger is not approved for a specific application, an approved sight gauge and mounting plate with the widest allowed opening shall be used. Regardless of the width of the opening, the scale plates shall not extend past the bevel of the retaining plate opening by more than $1 \mathrm{~mm}$ (approximately $0.04 \mathrm{in}$ ) to allow the best possible view of the liquid level. 


\subsection{Scale Plates}

\subsubsection{Material}

The scale plate shall be rigid and resistant to corrosion and discoloration (i.e., anodized aluminum, clear coated aluminum, or stainless steel).

\subsubsection{Mounting}

There shall be a sufficient number of scale brackets (minimum of two per scale plate) to hold the plate firmly. These brackets will be independent of the sight gauge retaining plate bolts. The scale plates shall be securely attached to the brackets and be provided with a means for sealing.

\subsubsection{Location}

The scale plates shall be mounted on the sight gauge mounting plate, parallel to the face of the reflex liquid level gauge.

\subsubsection{Parallax}

To minimize the effects of parallax, the graduated edge of the scale plates shall be bent in toward the sight gauge in conformation with the angle of the mounting plate bevel. When viewed from directly in front of the sight gauge, the graduated edge(s) of the scale plate(s) shall be within $\pm 1 \mathrm{~mm}$ (approximately \pm 0.04 in) of the line of view along the perpendicular edge of the mounting plate for the sight gauge.

\subsubsection{Maximum liquid level visibility}

In order to allow the best possible view of the liquid level, the scale plates shall not extend past the bevel of the retaining plate opening.

\subsubsection{Adjustment}

\subsubsection{Top scale plate(s)}

Movement of the top scale plate(s) of a pressurized volumetric field standard prover shall be used to adjust the volume of the prover. Adjustment or removal of the upper scale plate(s) shall not require loosening, removal, or any other manipulation of the sight gauge retaining plate bolts.

\subsubsection{Incremental adjustment}

Where the design of the scale adjustment provides for movement of the scale by increments only, the maximum increment shall be no larger than $25 \%$ of the smallest scale division.

\subsubsection{Lower scale plate(s)}

The lower scale plate(s) of a pressurized volumetric field standard prover shall be fixed in position with provision for sealing. Removal of the lower scale plate(s) shall not require loosening, removal, or any other manipulation of the sight gauge retaining plate bolts.

\subsubsection{Sealing}

All adjustments shall be provided with a means for sealing which will prevent movement or play. Removal or movement of any adjusting mechanism or scale plates (top and bottom) shall not be possible without breaking the seal. Any gauge movement or play in the adjustment mechanism or scale plates after tightening or sealing the adjustment mechanism shall be less than $25 \%$ of the smallest scale division. 


\subsubsection{Manufacturer's seals on new volumetric field standards}

A manufacturer that is not accredited by an Accreditation Body that is a signatory to the International Laboratory Accreditation Cooperation (ILAC) mutual recognition agreement (for the appropriate scope of volume calibration), shall not seal a new volumetric field standard unless a tag attached to the seal (or a label obscuring the view of the sight gauge) clearly states that calibration is required before the measure can be used for Weights and Measures applications.

\subsubsection{Scale Markings}

The graduation lines, numbers, and other inscriptions on the scale plate shall be permanent, durable, weather resistant, impervious to the liquids the volumetric field standard is intended to measure, and of a contrasting color to that of the gauge plate. All letters and numbers on a scale plate shall be legible and of adequate size, in no event smaller in height than $2 \mathrm{~mm}$ (approximately 0.08 in).

\subsubsection{Nominal volume and unit indication}

Scale plates shall be clearly marked with the nominal volume of the standard and the identification of the unit of measurement used on the scale plate. Proper abbreviations may be used for the unit of measurement (i.e., "gal”, "in", “L”, “mL”, etc.).

\subsubsection{Nominal volume line}

The nominal volume or zero lines on all top neck scale plates shall extend across the entire width of the scale plate (except as allowed for dual unit scale plates) and shall be clearly identified with the nominal volume of the volumetric field standard.

\subsubsection{Bottom zero line}

The bottom zero scale plate on of a pressurized volumetric field standard prover shall have a line extending across the entire width of the scale plate. This line shall be clearly marked as the “zero" or " 0 ” line.

\subsubsection{Additional marking}

The intended method of use, either "To Contain" or "To Deliver" shall also be clearly marked on the top scale plate. LPG and Anhydrous Ammonia provers are typically used "To Deliver."

\subsubsection{Graduation Lines}

\subsubsection{Graduation line length - Major divisions}

Convenient major (numbered) graduation lines, consistent with the measurement system used, shall meet with the maximum value requirements listed in Tables 1 and 2. Major graduations shall be numbered to indicate the volume and shall be twice the length of any subdivision lines. Major divisions shall be at least $6 \mathrm{~mm}$ (approximately $0.24 \mathrm{in}$ ) in length.

\subsubsection{Graduation line length - Subdivisions}

Any subdivision graduation lines shall be at least $3 \mathrm{~mm}$ (approximately $0.12 \mathrm{in}$ ) in length.

4.8.6.3 Graduation line width

Graduation lines shall be of uniform width and not more than $0.6 \mathrm{~mm}$ (approximately $0.024 \mathrm{in}$ ) or less than $0.4 \mathrm{~mm}$ (approximately 0.016 in) wide. 


\subsubsection{Line position}

All graduation lines shall extend to the edge of the scale plate nearest to the sight gauge.

\subsubsection{Graduation line spacing}

The minimum distance between the center of any adjacent graduations lines shall be $1.6 \mathrm{~mm}$ (approximately $1 / 16$ th in or 0.0625 in) and the lines shall be evenly spaced.

\subsubsection{Scale Plate Units}

The basic scale on metric standards shall be milliliters. The basic scale on U.S. Customary standards shall be decimal gallons ( 0.1 gal). Maximum graduation volumes are listed in Table 1 (metric) and Table 2 (U.S. Customary). Subdivision graduations (if present) shall be either onehalf $(1 / 2)$, one-fourth $(1 / 4)$, one-fifth $(1 / 5)$, or one-tenth $(1 / 10)$ of the volume of the major divisions.

\subsubsection{Additional bottom scale plate graduations}

Additional graduations are allowed for the convenience of the user in the evaluation of wet down characteristics of the vessel. If present, these graduations will be clearly differentiated from the zero line and clearly identified. If present, it is recommended that the bottom scale plate major graduations be $50 \mathrm{~mL}$ (0.01 gal) and minor divisions (subdivisions) $25 \mathrm{~mL}$ (0.005 gal), consistent with the measurement system used.

\subsubsection{Dual unit scale plates}

A volumetric field standard graduated in multiple (dual) units, shall have each nominal capacity mark clearly identified. The units of measure will also be clearly identified for each scale.

4.8.7.3 Dual units - Two scale plates

If two scale plates are used with dual unit scales, each shall be capable of being adjusted and sealed independently. Both shall be adjusted as close to nominal as possible during calibration.

4.8.7.4 Dual units - Single scale plate

A single piece dual unit scale plate is acceptable as long as the units are clearly defined, the two scales are clearly separated, the conversion between units across the scale plate is accurate, and each scale unit is clearly identified.

\subsubsection{Lack of confusion}

Additional care must be taken in the design of any dual scale plate(s) to ensure there is no confusion between units.

\subsubsection{Dual Scale Calibration}

A calibration certificate for a volumetric field standard with dual units must include calibration values for both scale plates. If the secondary scale was adjusted based on conversion of the units of the primary scale, it must be clear which scale was adjusted based on the calibration and which was adjusted based on the mathematical conversion (e.g., a 25 gal calibration with nominal zero adjusted to 25.0 gal and a $95 \mathrm{~L}$ nominal mark adjusted to coincide with the +0.096 gal indication on the U.S. Customary scale plate based on the calculated conversion that $95 \mathrm{~L}$ is approximately $25.096 \mathrm{gal})$. 


\subsubsection{Span of Graduations}

The graduated section of the scale plate shall cover at least $4 \%$ of the nominal volume of the prover. The scales shall be graduated both above and below the nominal capacity graduation by an amount not less than $1.5 \%$ of the nominal volume of the pressurized volumetric field standard prover.

NOTE: If a sight gauge is used that allows viewing of more than the minimum required, graduations should span the entire sight gauge. If $1.5 \%$ of the volume is above the nominal value, $2.5 \%$ must be below the nominal value to equal 4 percent.

\subsection{Fill and Discharge (Pump Off) Lines and Valves}

Two fast acting shut off valves specifically designed for LPG and/or anhydrous ammonia must be positioned at the bottom of the lower neck of the pressurized volumetric field standard, below the bottom zero level, to allow filling and draining of the prover. These valves must be protected with appropriate excess flow and/or back check valves. These valves must comply with UL Standard 125, Valves for Anhydrous Ammonia and LP-Gas (Other Than Safety Relief) and any other applicable safety standards.

\subsection{Bleed Lines}

A bleed line is a valve and piping attached to the bottom fill valve or to the piping between the bottom fill valve and the prover body to facilitate the adjustment of the zero level.

NOTE: Bleed lines present both safety and environmental hazards associated with venting LP gas or anhydrous ammonia to the atmosphere. Any existing bleed line that is removed should have the opening plugged with an appropriate ASME schedule 80 plug. Appropriate sealant tape or joint compound must be used to ensure the plug is leak free.

\subsubsection{Anhydrous Ammonia Provers}

A bleed line is not allowed for provers used exclusively with anhydrous ammonia. The discharge pump and valve shall be used for the final adjustment of the bottom zero level.

\subsubsection{LPG Provers}

Bleed lines are permitted on provers used exclusively with LP gas. When present, the bleed line shall extend to at least the height of the prover and be vented away from operator locations. The area around the prover shall be well ventilated during use. The bleed line shall be protected to prevent moisture from getting into the bleed line, freezing, and to prevent other blockages.

\subsection{Thermometer Wells and Thermometers}

\subsubsection{ASME Compliance}

All thermometer wells shall comply with the requirements of the ASME International Boiler and Pressure Vessel Code, Section VIII, Pressure Vessels. 


\subsubsection{Position}

A thermometer well shall be installed on the main vessel of the pressurized volumetric field standard. It shall be located so that the inserted thermometer or digital thermometer display can easily be read by the operator when reading the prover meniscus.

\subsubsection{Design}

A well shall extend at least $20 \mathrm{~cm}$ (8 in) into the prover at a downward angle of at least $15^{\circ}$ from the horizontal plane to allow a temperature conducting liquid to be poured into the well. It will protrude $5 \mathrm{~cm}$ ( $2 \mathrm{in}$ ) out of the prover and will be filled with an adequate amount of temperature conducting liquid to cover the sensitive portion of the thermometer of temperature probe that is used. The thermometer well should be located so that its lower (closed) end is at the approximate center of the vertical cross section of the prover.

\subsubsection{Installation in Thermometer Wells}

Regardless of type, all thermometers must be installed in an appropriate thermometer well.

\subsubsection{Electronic Thermometers}

Any electronic thermometer must be intrinsically safe. Any electronic temperature probe, wiring, and associated digital display must meet the requirements of ANSI/ISA RP12.06.01, Recommended Practice for Wiring Methods for Hazardous (Classified) Locations Instrumentation Part 1: Intrinsic Safety and all other safety requirements applicable to electronics in flammable atmospheres.

\subsubsection{Liquid-in-Glass}

A thermometer well designed for liquid-in-glass type thermometers shall be sized to receive an armored liquid-in-glass thermometer. It shall be provided with a removable cap connected to the prover body by a security chain.

SAFETY NOTE: Mercury is extremely toxic. If mercury thermometers are used, care should be taken to prevent breakage (e.g., armored cases). Mercury spill kits should be available at all times these thermometers are in use. Mercury thermometers (of any type) should not be used with anhydrous ammonia. Some States have restricted the use of mercury thermometers, so the local jurisdiction should be contacted to determine whether thermometers containing mercury may be used.

\subsubsection{Bi-Metal Dial Face Thermometers}

Mechanical, bi-metal strip, dial face type thermometers may be used if they meet the accuracy and stability requirements of applicable meter calibration procedures (i.e., NIST Handbook 1056, Specifications and Tolerances for Reference Standards and Field Standard Weights and Measures, 6. Specifications and Tolerances for Thermometers) and prover calibration procedures (NIST IR 7383 Selected Volume Procedures, SOP 21, Recommended Standard Operating Procedure for Calibration of LPG Provers). If used, these thermometers must be installed in an appropriate thermometer well.

\subsubsection{Provision for Calibration}

Any thermometer or temperature probe that is installed must be easily removable for periodic calibration or replacement if damaged. Temperature measurements shall be accurate to the level 
required by the applicable device testing requirements and traceable to naturally occurring intrinsic or national standards covering their range of use.

\subsubsection{Additional Thermometer Wells}

For larger prover volumes than identified in this handbook, more than one thermometer well should be spaced at two or three points in the upper, middle, and lower portions of the prover body. They should be placed at points equally spaced around the circumference of the prover. They should be positioned so that they can be easily read and averaged by the operator. An intrinsically safe system composed of multiple electronic probes attached to a single multichannel digital display is ideal for this application.

\subsection{Hardware}

\subsubsection{External Piping Requirements}

Piping shall be ASME Schedule 80 and all fittings and valves shall comply with National Fire Protection Association (NFPA) 58, Liquefied Petroleum Gas Code. Provers intended for use with anhydrous ammonia shall have series 300 stainless steel valves, fittings, and piping throughout.

\subsubsection{Pressure Gauge}

Provers shall be equipped with a calibrated pressure gauge piped to the vapor portion of the upper neck capable of reading 300 psig, with 5 pound per square inch or smaller graduations and mounted so that it is readable when the operator is reading the liquid meniscus level in the upper sight gauge of the prover. When practical, a liquid filled gauge is preferred. This pressure gauge shall be equipped with an appropriate shutoff valve between the gauge and the pressure vessel.

\subsubsection{Pressure Relief Valve}

At the top of the upper neck, there shall be a pressure relief valve (set at 250 psig for LPG and 300 psig for anhydrous ammonia) to protect the vessel. The type, placement, and maintenance of these valves must comply with UL Standard 132, Safety Relief Valves for Anhydrous Ammonia and LP-Gas and any other applicable safety standards.

\subsubsection{Safety collar}

The top of the neck shall have a collar designed to protect the pressure relief valve from accidental damage while allowing for complete drainage of water.

\subsubsection{Pressure relief valve cover}

In addition to a protective collar, the pressure relief valve shall have a cover that will prevent water from collecting that could freeze and plug the valve. The cover must protect the relief valve from water without interfering with the pressure relief function of the valve.

\subsubsection{Hydrostatic Relief Valves}

All portions of the plumbing containing liquid, or capable of trapping liquid (i.e., located between two valves), shall be equipped with an adequate hydrostatic pressure relief valve. These valves shall have a cover to prevent the accumulation of moisture that could freeze and block the valve, preventing the proper operation of the valves. Likewise, valve covers must not be tight enough to interfere with the proper operation of the valves. The type, placement, and maintenance of these valves must comply with UL Standard 132, Safety Relief Valves for Anhydrous Ammonia and LP-Gas and any other applicable safety standards. 


\subsubsection{Excess Flow Valves and Back Check Valves}

All pipe and hose attachments to the vessel shall comply with National Fire Protection Association (NFPA) 58, Liquefied Petroleum Gas Code. Where applicable, piping and hoses must be fitted with excess flow valves that will limit the escape of product if a pipe fails or a hose ruptures. Where appropriate (i.e., on the inlet line), back check valves may be used in lieu of excess flow valves.

\subsubsection{Vapor Pressure Equalization}

\subsubsection{Vapor return line (hose)}

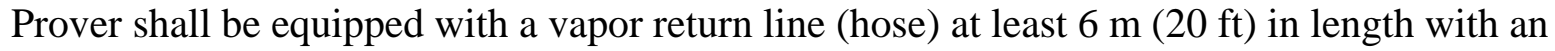
excess flow valve where the hose attaches to the neck of the pressurized volumetric field standard. It must have an appropriate (UL Standard 125) shutoff valve at end which attaches to the vapor return line on the tank of the truck or meter being tested. The vapor line connector shall either have a bleeder valve or be of the self-bleeding type to relieve pressure when the shutoff valve is closed before disconnecting.

\subsubsection{Diameter}

The vapor return line inside diameter shall be at least one-half the inside diameter of the liquid supply line.

NOTE: Restrictive vapor return lines or other system flow restrictions in addition to creating safety hazards, may contribute to proving errors.

\subsection{Leveling}

A prover not permanently installed shall have adequate provisions for leveling. A truck or trailer mounted prover shall be equipped with a minimum of three, and preferably four, leveling jacks to safely maintain a level and stable condition when under full liquid load.

\subsubsection{Establishment of Level Condition}

A pressurized volumetric field standard prover shall be leveled by placing a precision machinist spirit level vertically against the neck on at least two locations, $90^{\circ}$ apart around the circumference of the neck and adjusting the orientation of the standard until the neck is as close to vertical (plumb or perpendicular to the horizontal plane) as possible.

This method of determining the level condition (plumbing the neck) shall be used for the replacement and adjustment of levels on all mounted volumetric field standards. It shall retroactively be used to establish the reference level condition of all volumetric field standards, effective January 1, 2011.

NOTE: Due to the variability in the mounting of the glass level vials, spirit levels are not always accurate. A simple test for a vertical (plumb) level is to place the level on a nearly vertical surface, note the reading of the bubble in relation to the lines on the vial and then flip the level around $180^{\circ}$ (left to right) on the same surface. The position of the bubble in relation to the lines on the vial (the reading) should be the same. The same test can be applied for the horizontal level by placing it on a nearly level horizontal surface and flipping it around $180^{\circ}$ (left to right). In either case, if the positions of the spirit level bubble relative to the lines on the vial do not agree, the level should be replaced. 


\subsection{Levels}

\subsubsection{Position}

All mounted pressurized volumetric field standard provers shall be equipped with two, non-spring loaded, adjustable spirit levels that are mounted at right angles to each other, one approximately perpendicular, in the horizontal plane, to the sight gauge glass surface, on the upper cone or where best visible from a standing position. Each level shall be mounted on a sturdy shelf and be equipped with a protective cover. The adjusting and mounting screws shall have provisions for sealing.

\subsubsection{Leveling Jacks}

All leveling jacks shall operate freely and be stable under load. Load rating should be determined on the basis of $125 \%$ of the anticipated maximum load including the heaviest product to be tested.

\subsubsection{Level Sensitivity}

Spirit levels must have adequate sensitivity such that the level bubble will move by at least 0.1 inch when the prover is out of level in the orientation of the vertical plane passing through the center of the sight glass and the center of the neck cylinder (i.e., commonly referred to as "front to back") enough to cause an error of $25 \%$ of the volumetric field standard tolerance ( $0.0125 \%$ of the nominal volume).

NOTE: Commercially available spirit levels with a specification of 0.1 inch bubble offset per 45 min tilt or better meet this sensitivity requirement.

\subsubsection{Bulls Eye Bubble Levels}

On 200 L (50 gal) or smaller pressurized volumetric field standard provers, a precision "bull'seye" spirit level is permitted in lieu of two spirit levels, if it has sufficient sensitivity to ensure proper reading of the liquid level in the standard. Each level shall be mounted on a sturdy shelf either near the base of the sight glass or on the rim of upper cone, directly in front of the sight gauge assembly.

NOTE: Commercially available precision "bull's-eye" spirit levels with a specification of 0.1 in bubble offset per 45 min tilt or better meet this sensitivity requirement.

\subsubsection{Adjustment}

Spirit levels will be adjusted to indicate as close to center as possible and sealed in position when the volumetric field standard is level based on plumbing the neck (described in section 4.12.2). Levels permanently attached to a pressurized volumetric field standard prover must be verified each time the measure is calibrated.

\subsubsection{Auxiliary Levels}

Vehicle or trailer mounted pressurized volumetric field standards provers may have auxiliary levels mounted at a lower plane for operator convenience in adjusting leveling jacks. The primary levels on the prover (described above) shall be the reference levels for final leveling of the volumetric field standard. The primary levels should be used to set auxiliary levels. Auxiliary levels are only to be used for coarse leveling. 


\subsection{Workmanship, Finish, and Appearance}

\subsubsection{Air Entrapment}

Fabrication shall ensure that no pockets, dents, or crevices will be present which may entrap air or liquid, or impair the proper filling or draining of the standard. All drainage piping must be routed at a level lower than the bottom wet zero, especially in the area preceding valve(s). This will prevent an air pocket from forming when the prover is tested in the certifying laboratory.

\subsubsection{Finished Quality}

A field standard, together with its associated valves, piping, gauge, etc., shall be free of slag, scale, weld or solder splatter, grit, dirt, dents, interior rust, water or product residue, or any other foreign matter before shipment from the factory or before submission for calibration.

\subsubsection{Required Assemblies}

All parts of the gauge assemblies, and all piping and valves which affect the volume of a pressurized volumetric field standard shall be fully assembled by the manufacturer or supplier.

\subsubsection{Thread Connector Lubricant}

All threaded connections, including plugs and caps, shall be thoroughly lubricated with a suitable non-hardening paste, or pipe joint tape, and shall not leak. All threaded connections must be tested while the prover is under pressure using a suitable leak detection method to detect leaks.

\subsubsection{Valve Operation}

All valves shall operate freely and positively and shall not leak under normal operating pressures. Valves should be placed where the operator finds them to be easily accessible.

\subsubsection{Metal Joints}

All seams shall be filled and smooth to provide a continuous surface to prevent the entrapment of air or liquid, and shall not leak.

\subsubsection{Exterior Coatings}

The exterior surface of pressurized volumetric field standards made of low carbon steel shall be properly primed and coated with a glossy finish (white) or a color which is reflective and prevents any unnecessary heating of the product within the prover. Stainless steel pressurized volumetric field standards may also be painted in this way, but the natural stainless steel surface is acceptable (and recommended since it reduces the maintenance requirements of the painted surface).

\subsection{Other Requirements}

Evaluation of the following items is beyond the training and expertise of the typical laboratory metrologist. Each is covered by requirements and specifications of other organizations that supersede the requirements of this document. They are included for reference by manufacturers and as basic guidance to facilitate the detection of gross safety issues related to these systems. Calibration and evaluation of a pressurized volumetric field standard to the requirements of this handbook does not imply examination and approval of the items included in this section. 


\subsubsection{Return Pump}

The pump and piping shall be designed for use in LPG or anhydrous ammonia service and sized according to the prover volume to offer reasonable fill and drain times.

\subsubsection{Hoses}

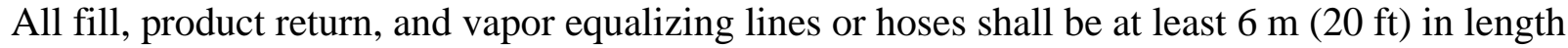
and meet the requirements of NFPA 58.

\subsubsection{Protective Caps}

The ends of all fill, product return, and vapor equalizing lines or hoses on a truck or trailer mounted prover shall be supplied with removable caps or mounted male fittings of like size to secure and cap hoses when not in use.

\subsubsection{Electrical Requirements}

\subsubsection{Electrical wiring}

All electrical wiring must be enclosed in appropriate conduit or approved flexible tubing. All electrical connections must be explosion proof. All wiring, including low voltage wiring shall meet the requirements of NFPA 58, Liquefied Petroleum Gas Code and/or other applicable articles of the latest edition of the NFPA 70, National Electrical Code.

\subsubsection{Ancillary equipment and instrumentation}

All additional electrical equipment and instrumentation used in conjunction with the pressurized volumetric field standard shall be intrinsically safe per the requirements of ANSI/ISA RP12.06.01, Recommended Practice for Wiring Methods for Hazardous (Classified) Locations Instrumentation Part 1: Intrinsic Safety.

\subsubsection{Braking System}

The truck or trailer mounted prover shall have an adequate braking system to meet all Department of Transportation (DOT) requirements and handle the load.

\subsubsection{Labeling and Placarding}

A pressurized volumetric field standard prover and any vehicle it is mounted on must be properly labeled and placarded according to DOT operational rules, NFPA 58, and other regulatory requirements. Local laws and regulations vary between jurisdictions. It is incumbent upon the manufacturer and purchaser of a pressurized volumetric field standard prover to be aware of and comply with local laws and regulations regarding the transport of hazardous materials.

\section{Tolerances (Maximum Permissible Errors)}

\subsection{Capacity Tolerance}

For volumetric field standards (test measures and provers) the maximum permissible errors shall be $\pm 0.2 \%$ of the nominal capacity. 


\subsection{Neck Tolerance}

\subsubsection{Neck Calibration Tolerance}

The requirement in 5.1 Capacity Tolerances, also applies to the scale intervals marked on both sides of the scale mark corresponding to the nominal capacity of a volumetric field standard (test measure or prover). This means that the volume represented by each scale mark over the entire range of the scale plate must be accurate within the maximum permissible error of $0.2 \%$ of the nominal capacity.

\subsubsection{Neck Uniformity Tolerance}

The maximum capacity tolerance between the nominal volume line and any other line on the scale shall be less than two (2) major scale divisions as listed in Tables 1 and 2. If smaller divisions or subdivisions are used, two (2) times the maximum allowed division listed in Tables 1 and 2 is the tolerance applied to the neck uniformity. The application of this tolerance must allow for the uncertainty of the neck scale calibration measurement. Therefore, in order to be rejected, the neck scale capacity error must exceed the value of two divisions plus the uncertainty of the neck scale calibration.

\section{$6 \quad$ Verification Requirements}

\subsection{Legal Requirements}

The specifications and tolerances specified in Tables 1 and 2 are intended to permit the use of the equipment in normal field testing operations as standards having nominal values. Weights and measures requirements, including but not limited to, inspection, testing, and sealing by a NIST recognized laboratory, shall be followed.

NOTE: Some States have requirements that are not documented here.

\subsection{Traceability}

Field standards used for legal metrology shall be traceable to national standards by calibration in a laboratory recognized by NIST Office of Weights and Measures or accredited to ISO/IEC 17025 to calibrate in that parameter, range, and scope as specified by local regulations.

\subsection{Calibration Certificates}

Acceptable accuracy and traceability to national or international standards shall be documented in a calibration certificate using accepted test methods. A calibration certificate must be prepared that states the calibration method used, the calibration medium (should be water), the nominal volume of the prover, the reference temperature, the reference pressure, the volumes at various applied pressures, the calibration error on the graduated neck, the expanded uncertainty ( $k=2$; or approximately a $95 \%$ confidence interval), the prover serial number, and the date. A pressure correction table and a temperature correction table should be provided with the calibration certificate. Additionally, guidance for correct application of the pressure and temperature corrections should be provided to the user. 


\subsection{Initial and Periodic Verification}

Field standards must be verified prior to use and rechecked as often as regulations or circumstances require, especially when damage is known or suspected. Pressurized volumetric field standard calibration may be established at 1 year intervals and extended or reduced based on historical evidence up to the limit determined by State or local regulations, but should not exceed 3 years due to possible leaking valves or seals which are often difficult to detect under field conditions.

\section{$7 \quad$ Test Methods and References}

To ensure the safety of metrologists, improve the accuracy of calibration, and to prevent environmental contamination, all pressurized volumetric field standard provers must be cleaned and thoroughly flushed with water before bringing inside for calibration. Internal contamination may create environmental and safety issues and reduce calibration accuracy. External contamination may create environmental pollution hazards. If there is evidence of residual contamination, the pressurized volumetric field standard prover should be rejected and removed from the building until it can be safely cleaned in a way that is not detrimental to the environment.

To facilitate calibration, it is suggested that all pressurized volumetric field standard prover systems be disassembled with excess flow and back check valves removed. These valves may interfere with the calibration process by leaking during pressurization. It is important that the pressure relief valve be left on the pressurized volumetric field standard prover during pressurization for the safety of the metrologists. Disassembly of piping makes it important that the final step of calibration is to reassemble the system and check all connections for leaks using an appropriate leak detection method while the prover is under pressure.

\subsection{NIST IR 7383 Selected Volume Procedures, SOP 21}

SOP 21, Recommended Standard Operating Procedure for Calibration of LPG Provers. Test methods shall comply with those documented in NIST IR 7383, Selected Volume Procedures or other nationally or international recognized procedures.

\section{Uncertainties}

\subsection{Legal Applications}

Uncertainties of the calibration must be evaluated according to the Evaluation of measurement data - Guide to the expression of uncertainty in measurement, $2008^{11}$ to ensure that the three-toone accuracy ratio of NIST Handbook 44 is maintained. As of 2009, the acceptance tolerance for liquid petroleum gas and anhydrous ammonia measuring devices is $0.6 \%$ of the measured volume. Therefore, the expanded uncertainty for calibration of a pressurized volumetric field standard must be less than $0.2 \%$ of the measured volume.

NOTE: LP gas and anhydrous ammonia measuring device tolerances should be evaluated at the time of use to ensure use of suitable standards, tolerances for standards, and applications. 


\subsection{Sources of Variation}

\subsubsection{Accuracy}

Accurate measurement demands the use of calibration equipment and standards with accuracy traceable to national or international standards and the use of standard procedures. Accurate and traceable measurements require the analysis of measurement uncertainty and an evaluation of that uncertainty to determine the adequacy for its intended use. In the case of LPG and anhydrous ammonia provers used in weights and measures applications, the expanded uncertainty for calibration must be less than $0.2 \%$ of the measured volume. Further, the correction/error in the standard plus or minus the uncertainty must be less than the tolerance.

To achieve the required expanded uncertainty, the following estimates demonstrate the typical maximum standard uncertainties associated with major contributors in the calibration:

- laboratory standard(s): $0.01 \%$ of the volume of the standard prover per delivery (at $95 \%$ confidence interval);

- measurement process: $0.02 \%$ of the volume of the prover under test (repeatability, determined as standard deviation); and

- neck calibration: $0.05 \%$ of the neck volume (the neck volume is at least $4 \%$ of total volume) of the prover under test.

When these factors are combined in a root-sum-square method and multiplied by a $k$ factor of two (approximate $95 \%$ confidence interval), it provides an uncertainty of less than $0.2 \%$ of the measured volume. If any one of the factors listed is greater than what is noted in the above list, the other factors must be reduced to compensate when one desires to maintain the required values for the expanded uncertainty.

For the previous example, the values are combined as follows:

$$
2 * \sqrt{(0.01 / 2)^{2}+0.02^{2}+(0.05 * 0.04)^{2}}+\mid \text { Prover Error } \mid \leq \text { Tolerance }(0.2 \%)
$$

To achieve the necessary accuracy, the corrected volume depends on:

- $\quad$ use of proper temperature corrections;

- $\quad$ the uncertainty associated with the cubical coefficient of thermal expansion;

- $\quad$ the accuracy of temperature measurements;

- $\quad$ correction for the compressibility of water; and

- $\quad$ use of an accurate pressure gauge.

- A single standard (as few as possible) should be used in the calibration of a pressurized volumetric field standard.

- the use of a proper “wet down” prior to calibration or use;

- $\quad$ whether gravity drain is used during calibration or whether the volume of water is eliminated by pumping;

- $\quad$ differences in drain between calibration and use for both the standard (reduced drain size) and the prover;

- $\quad$ wetting characteristic differences between water and LPG or anhydrous ammonia; 
- the cleanliness of the prover (sight glass and inner surface) and calibration medium;

- prover retention characteristics related to inside surface, contamination or corrosion, and total drain times;

- possible air entrapment in the water; and

- the ability to properly read the meniscus.

Proper reading of the meniscus must be followed to prevent additional error in the calibration and field use (see NIST IR 7383 Selected Volume Procedures, Good Measurement Practice 3).

If the same pressure gauge is used during calibration and during meter verification, errors due to inaccuracy of the pressure gauge should be minimized.

\subsubsection{Repeatability}

A pressurized volumetric field standard must be capable of repeating within $0.02 \%$ of the test volume during calibration. Repeatability problems may be the direct result of poor prover design, material corrosion over time/use, a leak in the valves or seals of the prover, or due to contamination and lack of cleanliness, and must be corrected before calibration can be completed. 
Table 1. Metric specifications and tolerances for pressurized volumetric field standards

\begin{tabular}{|c|c|c|c|c|c|}
\hline $\begin{array}{c}\text { Size } \\
\text { Liters } \\
(\mathrm{L})\end{array}$ & $\begin{array}{c}\text { Tolerance } \\
(\mathrm{mL}) \\
( \pm 0.2 \%)\end{array}$ & $\begin{array}{c}\text { Maximum } \\
\text { Graduations } \\
(\mathrm{mL})\end{array}$ & $\begin{array}{c}\text { Total Neck } \\
\text { Volume on } \\
\text { Scale } \\
(\mathrm{L})\end{array}$ & $\begin{array}{c}\text { Maximum } \\
\text { Upper Neck } \\
\text { Inside Diameter } \\
(\mathrm{in})\end{array}$ & $\begin{array}{c}\text { Lower Neck } \\
\text { Inside Diameter } \\
\text { (in) }\end{array}$ \\
\hline 100 & 200 & 50 & 4 & 5 & 4 \\
\hline 200 & 400 & 100 & 8 & 6 & 4 \\
\hline 500 & 1000 & 200 & 20 & 12 & 4 \\
\hline 1000 & 2000 & 200 & 40 & 18 & 4 \\
\hline 2000 & 4000 & 500 & 80 & & 4 \\
\hline
\end{tabular}

Table 2. U.S. Customary specifications and tolerances for pressurized volumetric field standards

\begin{tabular}{|c|c|c|c|c|c|c|}
\hline \multirow{2}{*}{$\begin{array}{l}\text { Size } \\
\text { (gal) }\end{array}$} & \multicolumn{2}{|c|}{$\begin{array}{l}\text { Tolerance* } \\
( \pm 0.2 \%)\end{array}$} & \multirow{2}{*}{$\begin{array}{l}\text { Maximum } \\
\text { Graduations } \\
\text { (gal) }\end{array}$} & \multirow{2}{*}{$\begin{array}{l}\text { Total Neck } \\
\text { Volume on } \\
\text { Scale } \\
\text { (gal) }\end{array}$} & \multirow{2}{*}{$\begin{array}{c}\text { Maximum } \\
\text { Upper Neck } \\
\text { Inside Diameter } \\
\text { (in) }\end{array}$} & \multirow{2}{*}{$\begin{array}{c}\text { Lower Neck } \\
\text { Inside Diameter } \\
\text { (in) }\end{array}$} \\
\hline & $\left(\mathrm{in}^{3}\right)$ & (gal) & & & & \\
\hline 20 & 9 & 0.04 & 0.01 & 0.8 & 6 & 4 \\
\hline 25 & 12 & 0.05 & 0.01 & 1 & 6 & 4 \\
\hline 50 & 23 & 0.1 & 0.02 & 2 & 8 & 4 \\
\hline 100 & 46 & 0.2 & 0.05 & 4 & 12 & 4 \\
\hline 200 & 92 & 0.4 & 0.1 & 8 & 18 & 4 \\
\hline 300 & 139 & 0.6 & 0.1 & 12 & 18 & 4 \\
\hline 500 & 231 & 1 & 0.1 & 20 & 18 & 4 \\
\hline
\end{tabular}

*Values are rounded to the nearest appropriate unit and are not exact conversions between units. For a capacity intermediate between two capacities listed above, the tolerances and graduations prescribed for the lower capacity shall be applied. 
Appendix 1. Optional LPG and Anhydrous Ammonia Pressurized Volumetric Field Standards Evaluation Form

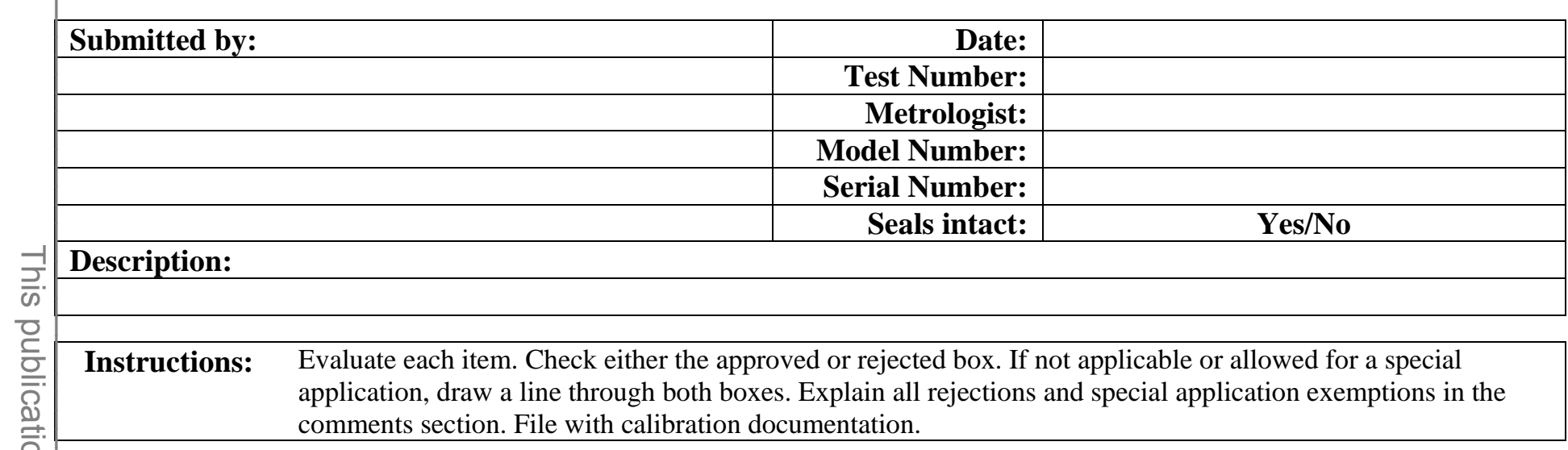

\begin{tabular}{|c|c|c|c|c|c|}
\hline \multicolumn{2}{|r|}{ Requirement } & \multirow{2}{*}{$\begin{array}{c}\text { HB 105-4 Ref. } \\
4.3\end{array}$} & \multirow{2}{*}{$\begin{array}{c}\text { Evaluation Tips } \\
\text { Check individual requirements for overall approval. }\end{array}$} & \multirow[t]{2}{*}{ Appd } & \multirow[t]{2}{*}{ Rej } \\
\hline & Identification & & & & \\
\hline 1 & Identification placement & 4.3.1 & $\begin{array}{l}\text { Permanent, stainless steel plate, weather \& liquid } \\
\text { resistant, contrasting color? }\end{array}$ & & \\
\hline 2 & Nominal capacity & 4.3.2.1 & & & \\
\hline 3 & Reference temperature & 4.3 .2 .2 & & & \\
\hline 4 & Manufacturer information & 4.3 .2 .3 & Name and address? & & \\
\hline 5 & Model number & 4.3.2.4 & & & \\
\hline 6 & Serial number & 4.3 .2 .5 & May be combined in serial number if clear & & \\
\hline 7 & Material ID & 4.3.2.6 & $\begin{array}{l}\text { Material identified? Stainless steel } \square \text { Low- } \\
\text { carbon steel } \square \text { Other }\end{array}$ & & \\
\hline 8 & $\begin{array}{l}\text { Cubical coefficient of } \\
\text { expansion }\end{array}$ & 4.3.2.7 & CCE marked on standard? & & \\
\hline 9 & Drain time & 4.3 .2 .8 & & & \\
\hline 10 & ASME certification & 4.3.2.9 & Year: & & \\
\hline 11 & Maximum working pressure & 4.3.2.10 & Pressure: & & \\
\hline 12 & $\begin{array}{l}\text { Date and pressure to which } \\
\text { hydrostatically tested }\end{array}$ & 4.3.2.11 & Date: ___ Pressure: & & \\
\hline 13 & ID upper and lower necks & 4.3.2.12 & Upper: _ _ Lower: _ & & \\
\hline 14 & Limitations on Use & 4.3.3 & Note any limitations on use: & & \\
\hline 15 & Product labeling & 4.3.4.1, 4.3.4.2 & Labeled LPG $\square$ or Anhydrous Ammonia $\square$ only? & & \\
\hline \multirow{3}{*}{16} & \multirow{3}{*}{ Construction material } & \multirow{3}{*}{ 4.4.1, 4.4.2, 4.4 .3} & ASME code compliance marked? & & \\
\hline & & & LPG: Stainless or low carbon steel? & & \\
\hline & & & Anhydrous Ammonia: Stainless Steel? & & \\
\hline 17 & Body and Shape & 4.5.1, 4.5.2, 4.5.3 & $\begin{array}{l}\text { Circular cross section in horizontal plane? } \\
\text { No fillers, adjusting plugs or cavities? } \\
\text { Shape ensures emptying, support? }\end{array}$ & & \\
\hline \multirow{3}{*}{17} & Neck (top) & \multirow{3}{*}{4.6} & Uniform, seamless, ID & & \\
\hline & Neck (hottom) & & Uniform, seamless, ID & & \\
\hline & Neck (Dotıom) & & Drain plug? & & \\
\hline \multirow{3}{*}{19} & \multirow{3}{*}{ Sight gauges } & \multirow{3}{*}{4.7} & Top: Reflex, clear, unbroken? & & \\
\hline & & & Scale range $\geq 4 \%$ of nominal capacity? & & \\
\hline & & & Bottom: Wet zero, reflex, clear, unbroken, $\geq 6$ in? & & \\
\hline 20 & Sight gauge mounting plate & 4.7 .3 & $\begin{array}{l}\text { Width of opening at least } 1 / 2 \text { inch unobstructed, all } \\
\text { bolts present and tight }\end{array}$ & & \\
\hline \multirow{3}{*}{21} & \multirow{3}{*}{ Scale plate construction } & \multirow{3}{*}{ 4.8.1, 4.8.2 } & Rigid, corrosion \& discoloration resistant? & & \\
\hline & & & Top: Mounting, does not obstruct view? & & \\
\hline & & & Bottom: Mounting, does not obstruct view? & & \\
\hline 22 & Adjustment & 4.8 .3 & Top adjustment, stable, $\leq 25 \%$ scale division? & & \\
\hline
\end{tabular}




\begin{tabular}{|c|c|c|c|c|c|}
\hline \multicolumn{2}{|r|}{ Requirement } & \multirow{2}{*}{$\begin{array}{c}\text { HB 105-4 Ref. } \\
4.8 .4\end{array}$} & \multirow{2}{*}{$\begin{array}{c}\text { Evaluation Tips } \\
\text { Adequate, no removal/movement of scale plates? }\end{array}$} & \multirow[t]{2}{*}{ Appd } & \multirow[t]{2}{*}{ Rej } \\
\hline 23 & Sealing & & & & \\
\hline \multirow{4}{*}{24} & \multirow{4}{*}{ Scale plate markings } & \multirow{4}{*}{4.8 .5} & Permanent and legible? & & \\
\hline & & & Nominal volume \& unit abbreviations? & & \\
\hline & & & Nominal \& zero lines? Top $\square$ Bottom $\square$ & & \\
\hline & & & “To Contain” $\square$ or “To Deliver” $\square$ & & \\
\hline \multirow{3}{*}{25} & \multirow{3}{*}{ Scale plate construction } & \multirow{3}{*}{ 4.8.6 } & Graduation spacing $(\geq 1.6 \mathrm{~mm}) \&$ width? & & \\
\hline & & & Bottom scale plate - zero line? & & \\
\hline & & & Adequate provisions for sealing? & & \\
\hline \multirow{4}{*}{26} & \multirow{4}{*}{ Scale plate graduations } & \multirow{4}{*}{$\begin{array}{c}4.8 .7 \\
\text { Table } 1 \\
\text { Table } 2\end{array}$} & Major Divisions? & & \\
\hline & & & Yes $\square$ No $\square$ Compliant? & & \\
\hline & & & Yes $\square$ No $\square$ Compliant? & & \\
\hline & & & Lack of confusion? & & \\
\hline 27 & Span of graduations & 4.8 .9 & Percent of nominal $(\geq 4 \%)$ ? & & \\
\hline 28 & Fill / discharge line, valves & 4.9 & Fast acting valves, piping below zero? & & \\
\hline 29 & Bleed lines & 4.10 & $\begin{array}{l}\text { Properly Routed. If removed, port is plugged with } \\
\text { the appropriate ASME schedule } 80 \text { plug. }\end{array}$ & & \\
\hline \multirow{2}{*}{30} & \multirow{2}{*}{ Thermometer wells } & \multirow{2}{*}{4.11} & Number of wells: & & \\
\hline & & & Placement of wells, calibration provision? & & \\
\hline 31 & External piping & 4.12 .1 & Schedule $80 ?$ & & \\
\hline 32 & Pressure gauge & 4.12 .2 & At least 300 psig x 5 psig? & & \\
\hline 33 & Pressure relief valve & 4.12 .3 & Safety collar, cover? & & \\
\hline 34 & Hydrostatic relief valve(s) & 4.12 .4 & All sections of piping that could trap liquid? & & \\
\hline 35 & $\begin{array}{l}\text { Excess flow / back check } \\
\text { valves }\end{array}$ & 4.12 .5 & $\begin{array}{l}\text { Placement back check on fill, excess flow other } \\
\text { large openings? }\end{array}$ & & \\
\hline 36 & Vapor return line & 4.12 .6 & Length, diameter, excess flow? & & \\
\hline 37 & Leveling & 4.13 & Leveling jacks adequate? & & \\
\hline \multirow[t]{2}{*}{38} & Levels & 4.14 & Adequate, protected, agree w/ plumb neck? & & \\
\hline & $\begin{array}{l}\text { Workmanship, finish, and } \\
\text { appearance }\end{array}$ & 4.15 & Check individual requirements for overall approval. & & \\
\hline 39 & Air entrapment & 4.15 .1 & No pockets, discharge piping below zero? & & \\
\hline 40 & Finished quality & 4.15 .2 & Joints leak free and smooth, no residues? & & \\
\hline 41 & $\begin{array}{l}\text { Assembly, leak free, valve } \\
\text { operation }\end{array}$ & $\begin{array}{l}4.15 .3,4.15 .4, \\
4.15 .5,4.15 .6 \\
\end{array}$ & $\begin{array}{l}\text { Everything assembled with pipe thread sealant, } \\
\text { valves convenient? }\end{array}$ & & \\
\hline \multirow[t]{2}{*}{42} & Coatings & 4.15 .7 & $\begin{array}{l}\text { Exterior paint light color, reflective, and in good } \\
\text { condition (non-stainless)? }\end{array}$ & & \\
\hline & Other Requirements & 4.16 & No Approval Implied - Note any gross problems. & & \\
\hline 43 & Return pump and hoses & $4.16 .1,4.16 .2$ & Adequate \& appropriate for purpose? & & \\
\hline 44 & Protective caps & 4.16 .3 & Supplied for all hoses? & & \\
\hline 45 & Electrical Requirements & 4.16 .4 & No exposed wiring or connections? & & \\
\hline 46 & Brakes & 4.16 .5 & Note if present. & & \\
\hline & Labeling and Placarding & 4.16 .6 & Note if present. & & \\
\hline & Test methods & 7 & Examine in preparation for calibration. & & \\
\hline 48 & Cleanliness & 7 & No residue, clear sight glass(es)? & & \\
\hline \multicolumn{2}{|r|}{ Requirement } & HB 105-4 Ref. & \multicolumn{3}{|l|}{ Comments } \\
\hline & & & & & \\
\hline & & & & & \\
\hline & & & & & \\
\hline & & & & & \\
\hline & & & & & \\
\hline
\end{tabular}




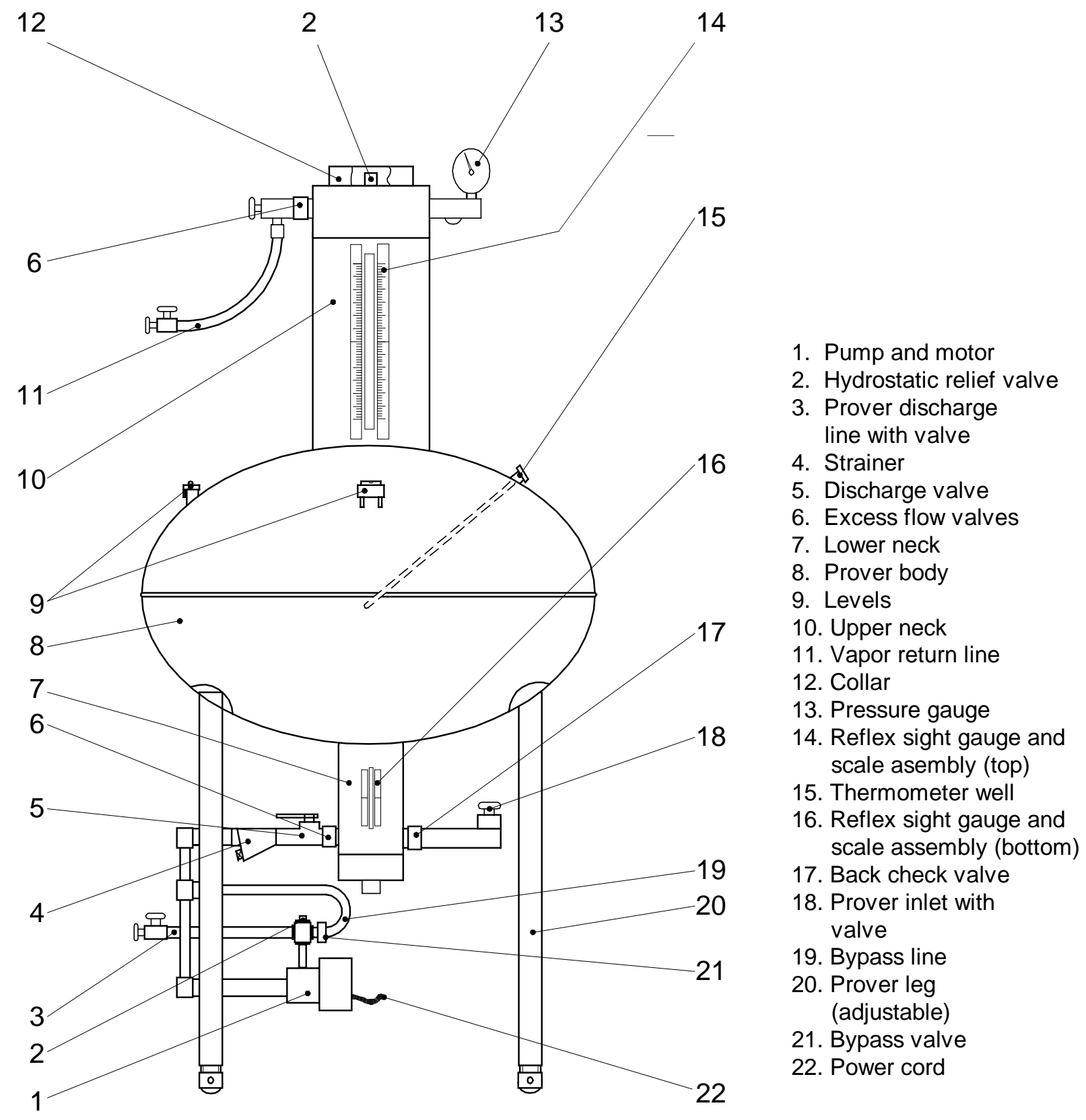

Figure 1. Schematic Drawing of a LPG and Anhydrous Ammonia Prover and Associated Hardware/Plumbing. 
TOP GAUGE PLATES
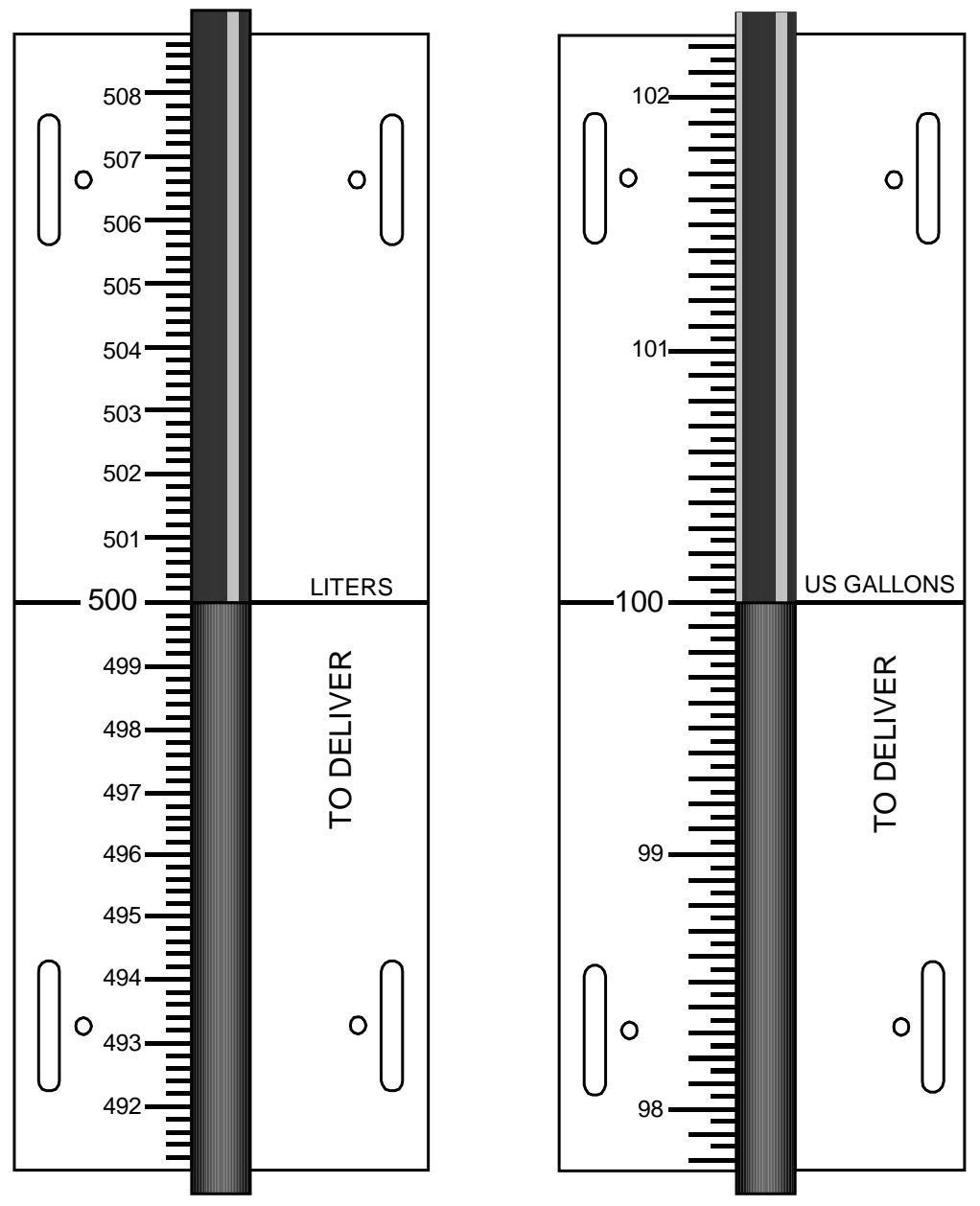

BOTTOM GAUGE PLATE
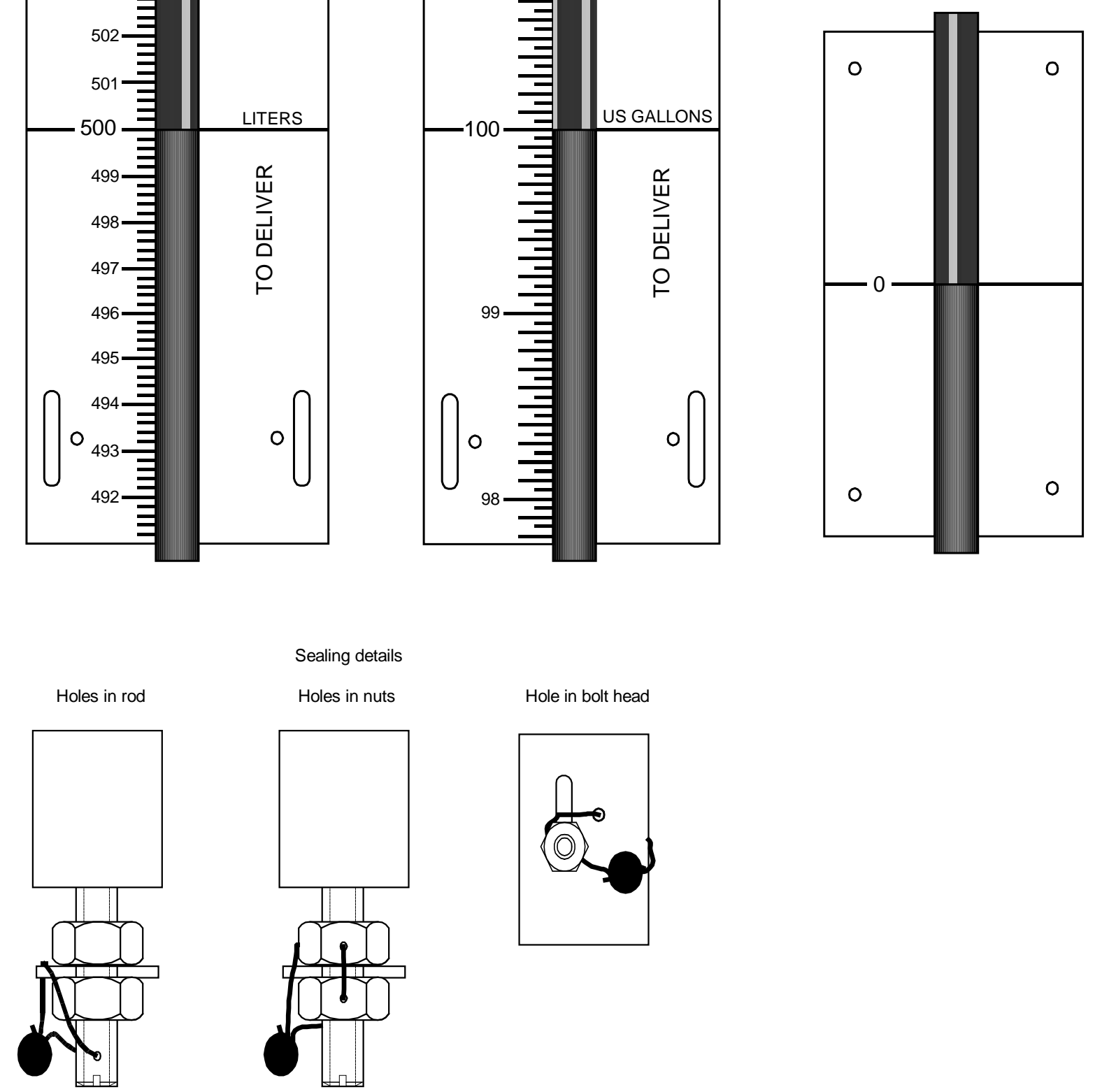

Hole in bolt head

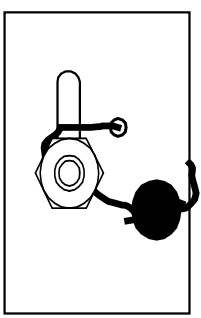

Figure 2. Schematic Drawing of Gauge Plates (Top and Bottom). 


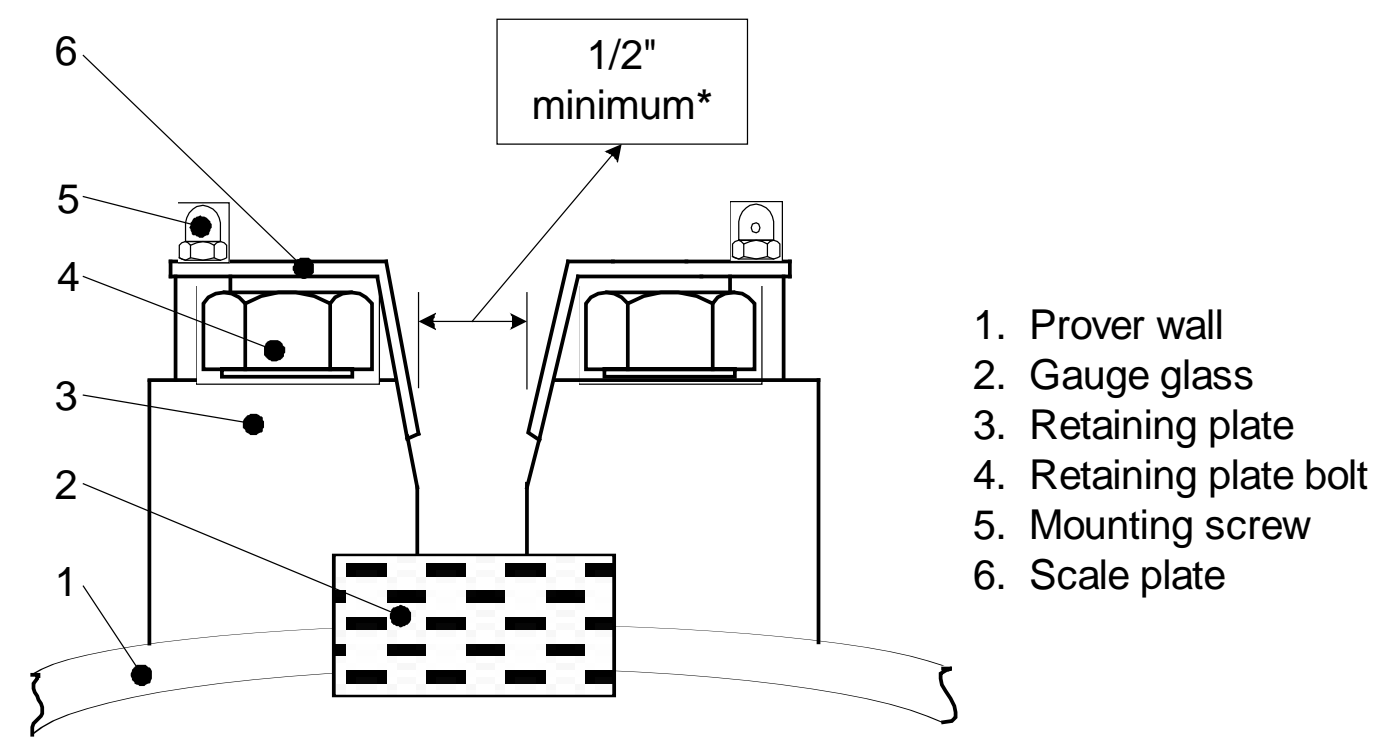

Figure 3. 100 gal Retention Plate (schematic).

*NOTE: Regardless of the width of the opening, the scale plates shall not extend past the bevel of the retaining plate opening by more than $1 \mathrm{~mm}$ (approximately $0.04 \mathrm{in}$ ). Optimally, the scale plates should not extend past the bevel at all in order to allow the best possible view of the liquid level. 


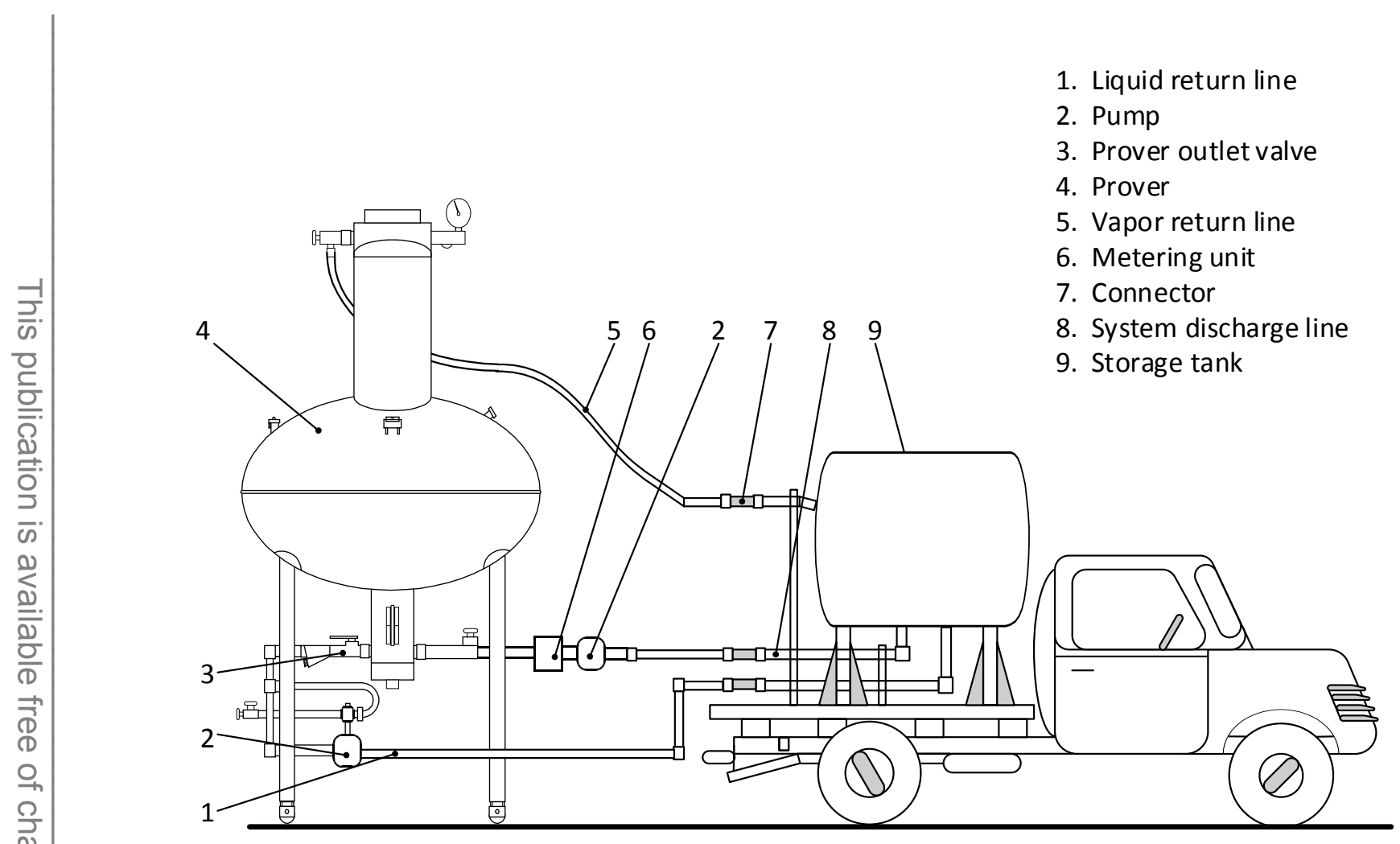

Figure 4. Schematic for Use of Prover in Meter Verification. 


\section{References}

1 American National Standards Institute (ANSI), 1819 L Street, NW, Suite 600, Washington, DC 20036, USA. WEB Site: http://www.ansi.org/

${ }^{2}$ American Petroleum Institute (API), 1220 L Street, NW, Washington, DC 20005-4070, USA. WEB Site: http://www.api.org/

${ }^{3}$ American Society for Mechanical Engineers (ASME), Three Park Avenue, New York, NY 10016-5990, USA. WEB Site: http://www.asme.org/

${ }^{4}$ American Society for Testing and Materials (ASTM), 100 Barr Harbor Drive, West Conshohocken, Pennsylvania 19428-2951, USA. WEB Site: http://www.astm.org/

${ }^{5}$ International Organization of Legal Metrology (Organisation Internationale de Métrologie Légale, OIML), 11, rue Turgot, F-75009 Paris, France. WEB Site: http://www.oiml.org/

${ }^{6}$ International Society of Automation (ISA), 67 Alexander Drive, PO Box 12277, Research Triangle Park, NC 27709, USA. WEB site: http://www.isa.org

${ }^{7}$ National Fire Protection Association (NFPA), 1 Batterymarch Park, Quincy, Massachusetts 02169-7471, USA. WEB Site: http://www.nfpa.org/

${ }^{8}$ National Institute of Standards and Technology (NIST), Office of Weights and Measures (OWM), 100 Bureau Drive Stop 2600, Gaithersburg, MD 20899-2600, USA. WEB Site: https://www.nist.gov/pml/weights-and-measures

${ }^{9}$ Underwriters Laboratories (UL), 2600 N.W. Lake Road, Camas, WA 98607-8542, USA. WEB Site: http://www.ul.com/

${ }^{10}$ US Department of Labor, Occupational Safety and Health Administration (OSHA), 200 Constitution Avenue, NW, Washington, D.C. 20210-0002, USA. WEB Site: http://osha.gov/

${ }^{11}$ Evaluation of measurement data - Guide to the expression of uncertainty in measurement, JCGM 100:2008, (GUM 1995 with minor corrections) WEB Site: http://www.bipm.org/en/publications/guides/gum.html 